\title{
Aquisição da Linguagem: Uma Retrospectiva dos Últimos Trinta Anos
} (Language Acquisition: A Survey of the Research of the Last Thirty Years)

Letícia Maria Sicuro Correa (PUC-Rio)

Abstract: A survey of the research on language acquisition is presented, in which the major trends, controversies and findings of the last 30 years are highlighted. The study of language acquisition carried out in Brazil is situated within the broader context of the research in this area. The perspectives of a theory of language acquisition are considered.

Key-words: Language acquisition; Linguistic development

Palavras-chave: Aquisição da linguagem; Desenvolvimento lingüístico

0. Introdução

Este artigo apresenta uma retrospectiva do estudo da aquisição da linguagem, situando a pesquisa em Aquisição da Linguagem conduzida no Brasil nos últimos 30 anos nos desenvolvimentos teóricos desse campo, que tomaram forma em meados deste século.

A aquisição da linguagem apresenta-se como uma questão fundamental na Teoria Lingüística e no estudo da cognição humana. O estudo da aquisição da linguagem visa a explicar de que modo o ser humano parte de um estado no qual não possui qualquer forma de expressão verbal e, naturalmente, ou seja, sem a necessidade de aprendizagem formal, incorpora a língua de sua comunidade nos primeiros anos de vida, adquirindo um modo de expressão e de interação social dela dependente.

O material empírico de que esse estudo dispõe são dados da produção, da percepção e da compreensão de enunciados lingüísticos por crianças, obtidos em condições naturais ou experimentais. O estudo de casos excepcionais em condições adversas é também da maior relevância, dado que esses casos permitem que se considerem as condições necessárias para que o processo de aquisição da linguagem transcorra sem ser significativamente alterado.

Toda criança é, em princípio, capaz de tomar a língua de sua comunidade como língua materna e de adquirir simultaneamente mais de uma língua. A 
aquisição de cada língua irá requerer a identificação de seu sistema fonológico, sua morfologia, seu léxico, o que há de peculiar em sua sintaxe e no modo como relações semânticas se estabelecem. Diante da variabilidade das línguas, a criança terá de lidar com uma série de variáveis nessa identificação. A despeito disso, o processo de aquisição da linguagem apresenta um padrão de desenvolvimento, em grande parte, comum aos diferentes indivíduos nas diferentes línguas, o que remete àquilo que, na linguagem, é comum `a espécie humana. Cabe a uma teoria da aquisição da linguagem explicar esse fato, considerando de que modo a aquisição de uma língua específica pode elucidar o processo pelo qual a aquisição espontânea de qualquer língua humana se realiza. Uma teoria da aquisição da linguagem pode, portanto, ser concebida como um modelo da dinâmica desse processo. Essa teoria deverá caracterizar o modo como a criança lida com o material lingüístico de que dispõe, extraindo dele informação relevante sobre a língua em questão, e explicar de que forma esse processo se faz viável para qualquer língua.

O desenvolvimento de uma teoria da aquisição da linguagem faz supor uma concepção ou modelo do estado estável do desenvolvimento a ser atingido e do estado inicial desse processo. Não há, contudo, no estudo da aquisição da linguagem, total consenso quanto ao modo de se conceberem os estados inicial e "final". Isso se deve, por um lado, à duplicidade de objetos a que o termo linguagem pode remeter - língua e forma de expressão verbal, o que dá margem a diferentes modos de se conceber o problema de aquisição. Por outro lado, as divergências decorrem do confronto de diferentes tradições ou posturas epistemológicas no tratamento de um problema interdisciplinar.

A Teoria Lingüística ${ }^{1}$, de orientação racionalista, parte do pressuposto de um estado inicial formulado em termos de uma Gramática Universal (GU) correlato lingüístico do tipo de programação biológica tida como necessária para que línguas apresentem as propriedades que as definem e sejam adquiridas num período de tempo relativamente curto. $O$ estudo da aquisição da linguagem no contexto do desenvolvimento da criança, apoiado numa concepção empirista de aquisição de conhecimento, tende a pressupor menos informação especificamente lingüística, ou seja, maior indeterminação quanto `a forma das línguas a serem adquiridas no estado inicial do processo.

${ }^{1} \mathrm{O}$ termo Teoria Lingüística remete aqui à vertente da Lingüística que visa a explicar o fato de línguas humanas serem adquiridas mais do que a prover descrições lingüísticas satisfatórias para outros fins. Até então, é a Linguiística Gerativista, mais especificamente na corrente chomskyana, que se tem colocado tal meta. 
Existem, ainda, dificuldades operacionais para uma aproximação com a Teoria Lingüística por parte daqueles que, no âmbito das ciências cognitivas, não se dedicam diretamente ao desenvolvimento de um modelo formal de língua, independentemente de seu posicionamento epistemológico. Modelos formais tendem a ser de grande complexidade e muitas das soluções encontradas para problemas descritivos apresentam-se pouco ou não motivadas. ${ }^{2}$ Grande parte do estudo do processo de aquisição da linguagem desenvolve-se, pois, de forma praticamente independente da Teoria Lingüística, ainda que a incorporação de uma teoria de língua numa teoria da aquisição da linguagem seja necessária. Na ausência de consenso quanto ao modo de se conceber a língua a ser adquirida e o ponto de partida do processo de aquisição tem havido mais divergência do que convergência em direção a um corpo teórico coerente, ao longo de cerca de meio século de pesquisa nessa área.

Pode-se, não obstante, vislumbrar o início da reversão desse quadro. Evidências empíricas provenientes de resultados da pesquisa psicolingüística e em áreas afins têm contribuído para tornar menos ideológica a discussão relativa à autonomia da língua no conjunto da cognição humana. Dados da percepção da fala por bebês (cf. Juckzyk, 1997) requerem que se atribua ao estado inicial do processo de aquisição da linguagem pelo menos um aparato perceptual especializado para o tratamento do material lingüístico. Indivíduos com deficiências cognitivas profundas, de origem genética ou congênita, que mantêm sua capacidade lingüística preservada, de um lado (Bellugi et al, 1993; Curtiss, 1981; Smith \& Tsimpli, 1995), e a existência de déficts especificamente lingüísticos no desenvolvimento, de outro (Bishop,1998), sustentam a hipótese da especialização de domínios cognitivos. As perdas seletivas na afasia (Grodzinky, 1990; Swinney \& Zurif, 1995) sugerem, ainda, haver especialização não apenas entre domínios cognitivos como no próprio domínio da língua. E a robustez do processo de aquisição de uma língua materna em condições socialmente adversas permite que se restrinjam as condições necessárias para o desenvolvimento lingüístico (Skuse, 1993). Com isso, a necessidade de se conceber uma programação biológica específica para a língua e para sistemas perceptuais dedicados ao processamento de material lingüístico revela-se hoje

${ }^{2} \mathrm{O}$ comentário de Chomsky é ilustrativo desse ponto:"We ask how much of what we are attributing to the faculty of language is really motivated by empirical evidence, and how much is a kind of technology, adopted in order to present data in a convenient form while covering up gaps of understanding. Not unfrequently, accounts that are offered in technical work turn out on investigation to be of roughly the order of complexity of what is to be explained, and involve assumptions that are not independently very well-grounded. (...)" (Chomsky, 1997, p.9-10). 
de forma mais clara do que em meados desse século.

Os desenvolvimentos recentes no âmbito da Teoria Lingüística, por sua vez, tendem a facilitar uma maior aproximação entre esta e o estudo do processo de aquisição da língua. Um modelo de GU formulado em termos de princípios universais e de parâmetros com um número fixo de valores possíveis facilita a formulação de hipóteses acerca do que se apresenta à criança como problema de aquisição (Chomsky, 1981; 1986). Em sua formulação mais recente (Chomsky, 1995 ; 1997), essa teoria passou a levar em conta a necessidade de caracterizar níveis de interface entre língua e sistemas de desempenho no modelo de língua interna (língua-I, de interna e intensional, Chomsky, 1986) a ser tomado como representativo do estado estável do processo de aquisição. Considerase a possibilidade mesma de estes sistemas influenciarem a forma como expressões lingüísticas se apresentam, ao definirem-se condições de legibilidade dos níveis de interface (Chomsky, 1997). Essa concepção contempla, de certo modo, a idéia de um "funcionalismo" perceptual há muito intuída por Bever (1970 a; b) (cf. 4), ao discutir a relação entre língua e sistemas perceptuais. Paralelamente, uma versão alternativa de GU, nos termos da chamada Teoria da Otimidade (Prince \& Smolensky, 1993; McCarthy \& Prince, 1993 apud Kager, 1999), fornece um modelo menos determinístico do estado inicial, tornando-se mais aceita por parte das correntes inicialmente mais refratárias à idéia de inatismo no estudo do desenvolvimento lingüístico. De qualquer forma, persiste a divergência quanto ao grau de indeterminação do estado inicial, o que remete a diferentes tipos de teorias de aquisição.

O estudo da aquisição da linguagem conduzido no Brasil inscreve-se nesse contexto teoricamente diversificado e assume direcionamentos próprios. Esse estudo teve início na década de 70, no auge da polêmica em relação `a chamada hipótese inatista (Chomsky, 1965) e ao grau de autonomia a ser atribuído ao desenvolvimento lingüístico em face dos demais aspectos da cognição. De modo a situar a pesquisa em Aquisição da Linguagem conduzida no Brasil no curso do desenvolvimento de uma teoria da aquisição da linguagem é necessário, pois, percorrer a trajetória desse campo de investigação e buscar entender o porquê de muito da controvérsia em torno do modo de caracterizar o processo de aquisição da linguagem.

A presente retrospectiva parte do problema da aquisição da linguagem formulado na Teoria Linguística e apresenta as principais direções tomadas pelo estudo do processo de aquisição da linguagem a partir dessa formulação. A principal controvérsia no que concerne à aquisição da linguagem, qual seja, 
o quanto de informação relativa à forma das gramáticas das línguas humanas atribuir ao programa biológico que caracteriza o estado inicial do processo de aquisição, manifesta-se no modo como a relação entre desenvolvimento lingüístico e cognitivo é abordada, no modo como a relação entre sintaxe e semântica no desenvolvimento lingüístico é concebida, na formulação de hipóteses acerca das condições ambientais ou interpessoais tomadas como necessárias para a aquisição de uma língua e na natureza dos procedimentos de aquisição propostos. Nesse artigo, cada um desses pontos será focalizado. Apresentar o percurso teórico do estudo da aquisição da linguagem sob uma perspectiva histórica e temática é, entretanto, proposta ambiciosa para os limites de um artigo. Não se deve, pois, esperar aprofundamento dos temas levantados, nem uma revisão por sub-áreas específicas. A razão de insistir-se numa caracterização abrangente, ainda que não exaustiva e, até certo ponto superficial, dos desenvolvimentos da pesquisa em aquisição da linguagem reside na carência de um material de leitura que facilite ao leitor pouco familiarizado com o campo uma rápida inserção na trajetória multidirecionada do mesmo.

O objetivo deste artigo é, pois, prover um mapa teórico básico (na medida do possível não tendencioso), para que o leitor tenha uma visão panorâmica do estudo da aquisição da linguagem nos últimos 30 anos. Espera-se que ele venha a ser capaz de identificar algumas das principais questões que essa pesquisa vem tentando responder, assim como a perspectiva teórica subjacente a estudos sobre tópicos específicos que venha a encontrar. Espera-se, em particular, que possa posicionar o estudo da aquisição da linguagem conduzido no Brasil no desenvolvimento de uma teoria da aquisição da linguagem. Visase, com isso, não só motivar o leitor a agregar-se aos poucos que, neste país, se dedicam a essa área, como facilitar-lhe uma inserção nesse campo de investigação que não fique restrita aos termos de uma dada abordagem.

1. O problema lógico da aquisição da linguagem e o contexto em que foi formulado

A pesquisa em Aquisição da Linguagem tomou impulso com a formulação do problema lógico aquisição da linguagem pela Lingüística Gerativista. Esta, ao apresentar um modelo formal de gramática como modelo da competência linguística de um falante/ouvinte abstrato, defrontou-se com a tarefa de explicar o fato de gramáticas (línguas) serem identificadas (num conjunto de gramáticas possíveis) a partir de um subconjunto das expressões por elas geradas, num período de tempo relativamente curto. A formulação desse problema levou a 
Teoria Lingüística a conceber restrições à forma das gramáticas de línguas naturais como parte da dotação biológica característica da espécie humana, o que é formalizado como Gramática Universal (GU) (Chomsky, 1965). O problema da aquisição da linguagem é, portanto, originalmente concebido como um problema de identificação (no sentido de seleção de uma língua num conjunto de línguas possíveis) da língua materna pela criança.

Em função dos desenvolvimentos associados à chamada revolução cognitiva de meados desse século (cf. Gardner, 1986) ${ }^{3}$, a formulação do problema lógico da aquisição da linguagem pela Lingüística Gerativista despertou interesse no processo de aquisição, o qual passou a ser abordado por diferentes frentes: pela então emergente Teoria da Aprendibilidade ${ }^{4}$, vinculada `a Teoria das Gramáticas Formais ou Lingüística Matemática (ambas constituídas no contexto da Lingüística Gerativista), pela Psicologia do Desenvolvimento e pela Psicologia Cognitiva, particularmente no ramo que se constituiu como Psicolingüística a partir dos anos 60.

2. A concepção formal da aquisição da linguagem e o estudo do processo a partir de GU

De um ponto de vista abstrato, o processo de aquisição da linguagem foi considerado inicialmente pela Teoria da Aprendibilidade (Gold, 1967 apud Pinker, 1979; Hamburger \& Wexler, 1973; 1975; Pinker, 1979; 1989), que formula hipóteses sobre as propriedades a serem atribuídas a sistemas formais para que estes sejam identificados por um dado procedimento de aprendizagem (também definido abstratamente), em condições específicas (tais como, a presença ou ausência de feedback positivo ou negativo e a presença ou ausência de evidência negativa nos dados lingüísticos primários) (cf. Culicover, 1976).

Essa pesquisa demonstrou, por exemplo, que os modelos de gramática de línguas naturais então concebidos não apresentavam línguas passíveis de serem identificadas por um procedimento com propriedades também atribuíveis

${ }^{3}$ Esses desenvolvimentos incluem o tratamento de processos cognitivos em termos de processamento de informação no âmbito da Psicologia Cognitiva, o desgaste do paradigma behaviorista, afetando diretamente a Psicologia do Desenvolvimento, e o surgimento de uma Teoria de Gramáticas Formais vinculada à Teoria da Computação.

${ }^{4}$ Aprendibilidade é um termo cunhado a partir do inglês learnability e remete às propriedades a serem atribuídas a um sistema formal de gramática para que este possa ser identificado num conjunto de gramáticas formais, a partir de um subconjunto das expressões ou sentenças por ele geradas, tendo-se definido um dado procedimento de aprendizagem. 
ao procedimento humano de aquisição da primeira língua. Ou seja, por um procedimento de aprendizagem que não tem acesso ao conjunto de sentenças já processadas ao lidar com uma nova sentença ou expressão da língua (e sim à gramática da língua), que não se baseia em evidência negativa e é insensível a feedback negativo imediato quanto à forma, como sugerem observações sobre o papel da correção explícita do adulto à forma dos enunciados produzidos por crianças (cf. Ingram, 1989).

Fora dessa abordagem estritamente formal, o estudo da aquisição da linguagem vinculado à Teoria Lingüística nos anos 70 apresentava uma vertente preocupada em formular hipóteses sobre o processo de aquisição levando em conta, diretamente, dados do desempenho lingüístico de crianças. Buscavase, para isso, avaliar sua competência lingüística por meio de experimentos de compreensão (cf. artigos apresentados na coletânea de Tavakolian, 1981, como representativos dessa abordagem). Esse tipo de abordagem não se revelou, contudo, dos mais produtivos. Por um lado, a concepção de gramática da época $3 / 4$ gramática como sistemas de regras, fazia com que o problema da aquisição de uma língua fosse concebido como de aquisição de suas regras (tais como relativização e apassivação), concepção esta que se revelou equivocada (cf. Chomsky, 1981). Por outro lado, a análise e interpretação dos dados do desempenho lingüístico da criança encontrava uma série de dificuldades. Esses dados eram tomados como reflexo da competência lingüística da criança, sem que a mediação entre esta e sistemas de desempenho fosse considerada. Alterações no desempenho lingüístico eram, então, entendidas como alterações no estado da competência lingüística e processos maturacionais autônomos, no domínio de GU, apresentavam-se como explicação privilegiada para tais alterações. (cf. Corrêa, 1996).

Os desenvolvimentos no âmbito da Teoria da Aprendibilidade nos anos 70 contribuíram para que a Teoria Lingüística chegasse a um modelo de GU formulado em termos de princípios universais e parâmetros (como, por exemplo, a posição do complemento em relação a um núcleo lexical) cujos valores seriam fixados (dentre um conjunto de valores preferencialmente binários) a partir do contacto da criança com uma dada língua (Chomsky, 1981; 1986). Dessa forma, o problema da aquisição da linguagem passou a ser entendido, basicamente, como um problema de fixação de parâmetros e de aquisição do léxico da língua. Uma vez que a fixação de um determinado parâmetro repercutiria em diferentes subsistemas da língua, muito do que antes ficava dependente de aquisição específica passou a ser eliminado. A aquisição do léxico (cf. Clark, 1993), por outro lado, embora acentuada aos dois anos de idade, constitui um processo 
que pode estender-se até uma idade avançada, o que torna plausível supor tratar-se de um processo regido por fatores distintos dos que operam na sintaxe e na fonologia.

O estudo da aquisição da linguagem formulado em termos da fixação de parâmetros deu origem a uma série de questões teoricamente relevantes, como por exemplo: Deve-se assumir o pressuposto da continuidade, ou seja, o de que os princípios de GU estão acessíveis no estado inicial da aquisição da linguagem e o desenvolvimento diz respeito unicamente à fixação dos parâmetros? Ou deve-se assumir que esses princípios estão sujeitos a um cronograma maturacional tornando-se accessíveis de forma gradativa no desenvolvimento (Felix, 1992; Penner \& Wissenborn, 1996)? O que promoveria a fixação de um dado parâmetro? Por que, estando desde o início exposta a evidências relevantes ‘a fixação de um dado parâmetro, a criança parece "selecionar" informação (Borer \& Wexler, 1987)? A fixação de parâmetros envolveria procedimentos de aprendizagem ou de auto-desencadeamento (bootstrapping ${ }^{5}$ )? (Pylyshyn, 1977; Pinker, 1987). O quanto de exposição a evidências positivas relativas a um determinado valor é necessário para que parâmetros sejam fixados (Lightfoot, 1989; Randall, 1992)? Em que nível de encaixamento da oração estaria a informação necessária pada a fixação de parâmetros (Lightfoot 1989; Roeper \& Weisenborn, 1990)? Parâmetros podem ser refixados? Haveria um valor default (Hymes, 1986)? Haveria "erros" previsíveis no processo (Harris \& Weler, 1996)? (ver Meisel, 1997, para uma introdução às questões que orientam essa pesquisa).

A partir dessas questões, tem-se uma segunda geração de estudos do processo de aquisição da linguagem vinculados à Teoria Lingüística, que busca testar hipóteses relativas ao modelo de GU e ao processo de fixação de parâmetros nos dados do desempenho lingüístico de crianças, particularmente, nos dados da produção espontânea. Persistem, contudo, dificuldades metodológicas nessa abordagem. As evidências que sustentam as hipóteses formuladas são, de uma modo geral, negativas, ou seja, sustentam-se pela não observância de algo que não seria previsível pela teoria de GU em questão. Além disso, fatores relativos ao desenvolvimento de habilidades de processamento do material lingüístico podem ser determinantes do

\footnotetext{
${ }^{5} \mathrm{O}$ termo bootstrapping diz respeito a uma ação promovida por um sistema que desencadeia outra que afeta a ele próprio. Seu uso, no contexto da aquisição da linguagem, diz respeito a uma ação, proveniente do contato da criança com a língua de seu meio social, que irá desencadear ou operacionalizar o sistema computacional que estaria especificado num programa biológico
} 
desempenho lingüístico da criança num dado momento. Não é claro, pois, se evidências compatíveis com a hipótese de uma descontinuidade no desenvolvimento remetem necessariamente a diferenças quanto `a informação disponível a partir de GU num dado momento (cf. Kato, 1999) De qualquer forma, esse modo de investigação tem-se revelado produtivo.

Grande parte da pesquisa em Aquisição da Linguagem que tomou forma no Brasil a partir dos anos 80 vincula-se à pesquisa em Teoria Lingüística na âmbito do chamado modelo de Princípios e Parâmetros (Chomsky, 1981; 1986). Dados da produção de crianças na aquisição do português são considerados de modo a contribuir para essa teoria, apresentando evidências ou provendo soluções para problemas específicos de fixação paramétrica (cf. Kato, 1995). Tópicos como o sujeito nulo e o objeto nulo têm sido particularmente enfocados com base nesses dados, além de questões relativas à hipótese da continuidade, considerando-se a presença ou ausência de categorias funcionais nas gramáticas iniciais (ver Kato, 1999, para um levantamento de dissertações e teses nessa linha de pesquisa; Perroni, 1999; Simões, 1998).

No âmbito da fonologia, tem-se, também a partir da década de 80, uma linha de pesquisa em aquisição do português e desvios fonológicos do desenvolvimento fundamentada numa concepção de GU expressa nos termos da Fonologia Auto-segmental (Clements \& Hume, 1995) (Lamprecht, 1995; 1999; Hernandorena, 1995; 1996; 1999 a; 1999b; Mota, 1999; Ramos, 1999). Mais recentemente, avalia-se o potencial explanatório da Teoria da Otimidade como alternativa para dar conta desse tipo de dados (cf. Lamprecht (1999) e referências ali contidas).

\section{A aquisição da linguagem e o desenvolvimento da criança}

De um ponto de vista mais concreto ou não formal, o processo de aquisição da linguagem foi abordado por psicólogos do desenvolvimento, que passaram a prover descrições longitudinais do percurso evolutivo da aquisição do inglês (Brown, 1973; Menyuk, 1969; 1971; Bloom, 1970; 1973), retomando a tradição dos diários de bebês, de forma linguisticamente mais informada do que `a época de seus antecessores (Leopold, 1939-49 e Stern \& Stern, 1907 apud Blumenthal, 1970 e apud Ingram, 1989).

A influência da Teoria Lingüística sobre esta linha de investigação manifestou-se, de fato, mais no fornecimento de um instrumental descritivo para a apresentação de dados do desenvolvimento do que no de uma hipótese 
sobre a natureza do processo de aquisição da linguagem. A formulação desse processo, do ponto de vista da aprendibilidade de gramáticas, não se apresentava atraente para o estudo do desenvolvimento centrado na criança, talvez por abstrair a criança num procedimento de aprendizagem. Psicólogos do desenvolvimento e lingüistas punham-se, em grande parte, em distribuição complementar. Enquanto Chomsky manifestava-se céptico quanto à relevância de dados da fala de crianças para o estudo do processo de aquisição da linguagem (Chomsky, 1964, apud Allen \& van Buren, 1971, p.134), Roger Brown dizia-se pouco motivado a especular sobre dispositivos de aquisição da linguagem mal definidos (cf. Brown, 1973,p.19), fazendo referência à noção de LAD - Language Acquisition Device, introduzida por Chomsky (1965), de modo a materializar a idéia de que procedimentos de aquisição e sistemas perceptuais específicos, definidos como parte de uma faculdade de linguagem, seriam requeridos para que a criança viesse a lidar com os chamados dados lingüísticos primários.

Na verdade, a questão do que seria necessário atribuir ao estado inicial do processo de aquisição da linguagem não se apresentava claramente `a Psicologia Evolutiva. A indiferenciação do estado inicial do desenvolvimento por domínios cognitivos era o pressuposto básico da tradição empirista na qual a Psicologia se inseria. Logo, o discurso racionalista recuperado pela Lingüística Gerativista provocava reação entre psicólogos do desenvolvimento, por abalar seus fundamentos epistemológicos. Uma vez que as bases biológicas de uma possível diferenciação por domínios no estado inicial do processo eram apenas conjeturadas (Lennenberg, 1967), o discurso da Lingüística corria o risco de ser visto, na ótica de psicólogos de formação empirista, como um retrocesso para uma concepção pré-científica da atividade mental.

Nos anos 60-70, a Psicologia Evolutiva norte-americana, distanciandose do Behaviorismo, abria-se à influência do pensamento europeu através de traduções para o inglês dos trabalhos de Piaget ([1926] 1959; [1951] 1962; [1964], 1974) ${ }^{6}$, acerca do desenvolvimento cognitivo. Ao mesmo tempo, as idéias de Chomsky chegavam à Europa (Lyons, 1970; Aitichison, 1976), eram aparentemente absorvidas pela escola Piagetiana (Sinclair, 1976 a; 1976 b) e abalavam uma longa tradição funcionalista na Lingüística e uma forte tradição empirista na Filosofia (cf.Halliday, 1975; Bruner, 1983). Nesse contexto, as relações entre linguagem e cognição por um lado, e entre linguagem e

\footnotetext{
${ }^{6}$ As datas entre colchetes referem-se à edição original em francês.
} 
comunicação ou interação social, por outro, passaram a assumir o foco da atenção de psicólogos, lingüistas e filósofos, sendo esse interesse progressivamente absorvido por uma ampla comunidade intelectual, como pôde ser constatado no famoso "debate" entre Chomsky e Piaget, em 19757. (Piatelli-Palmerini, 1980).

Diante de diferentes perspectivas e abordagens, o estudo da aquisição da linguagem passou a ser dominado pela controvérsia. De um lado, a proposta inatista da Teoria Lingüística e, de outro, diferentes posturas em relação ao quanto de especificidade é necessário atribuir à língua/gem quando comparada a outros sistemas cognitivos e ao quanto de independência pode ser atribuída ao desenvolvimento lingǘ́stico no conjunto do desenvolvimento cognitivo. De um lado, a centralização do problema da aquisição da linguagem em seu aspecto sintático (cf.1) e, de outro, a preocupação com os conceitos e relações semânticas expressas na fala da criança e a hipótese de uma precedência da semântica sobre a sintaxe, no processo de aquisição. (Bloom, 1970; Schlesinger, 1971; Bowerman, 1973). De um lado, a idéia da precariedade do input lingüístico da criança (Chomsky, 1964 apud Allen \& van Buren, 1971) e, de outro, a caracterização da fala dirigida à criança como um registro peculiar (cf. Snow, 1986). De um lado, o desenvolvimento lingüístico tomando forma a partir da discriminação do sinal acústico da fala nos primeiros dias de vida (Eimas, 1974 apud Mehler \& Dupoux, 1990) e, de outro, o desenvolvimento lingüístico visto como fundado em habilidades comunicativas ou pragmáticas prélingüísticas (Bates, 1976).

Foi a partir dessa controvérsia que o interesse pela aquisição da linguagem foi difundido para além do mundo anglofônico e é no contexto teório dos anos 70 que a pesquisa em aquisição da linguagem tem início no Brasil. São dessa época os estudos pioneiros de de Lemos (1975), sobre a aquisição dos verbos ser e estar, refletindo, de certa forma, a confluência de diferentes tradições na Grã-Bretanha ${ }^{8}$, o estudo de Scliar-Cabral (1977), procurando alternativas teóricas para lidar com a descrição de gramáticas emergentes, e o trabalho de Mota Maia (Albano) (1975), analisando a negação na fala da criança, de modo a refletir sobre a proposta gerativista. É nessa década que tem início o projeto de Aquisição da Linguagem, coordenado por Cláudia de Lemos na UNICAMP,

\footnotetext{
${ }^{7}$ Evento que reuniu Piaget, Chomsky e expoentes de diferentes áreas do conhecimento como Fiolosofia, Biologia, Antropologia, dentre outras, para discurtirem a questão do estado inicial da aquisição da linguagem, nas perspectivas inatista e construtivista, ocorrido em 1975, na abadia de Royaumont, na França.

${ }^{8}$ Trabalho conduzido na Universidade de Edinburgh.
} 
a partir do qual irradiou, em grande parte, o interesse sobre esse tópico no país (cf. de Lemos, 1989 e Scliar-Cabral, 1989, para um levantamento dos trabalhos dessa época).

Foi uma época rica em idéias, que deu margem a muitos direcionamentos para o estudo da aquisição da linguagem. Ao mesmo tempo foi uma época povoada por mal-entendidos, devidos, até certo ponto, à não distinção entre diferentes tipos de questões: questões relativas à aquisição de uma determinada língua, ao desenvolvimento de habilidades de processamento lingüístico e ainda a formas de expressão dependentes de uma linguagem verbal. A interdisciplinaridade que passou a caracterizar o estudo da aquisição da linguagem, ao mesmo tempo que enriquecia o tratamento do problema, contribuía para uma flutuação conceitual que dificultava o debate, como pode ser observado nos diferentes usos de termos tais como estrutura profunda, universais lingüísticos, estratégias, gramática, semântica, dentre outros, na literatura de então.

Reconstituir um pouco dessa época, identificando os pontos de controvérsia e dissolvendo-a, quando possível, permite entender as principais questões que têm orientado o estudo da aquisição da linguagem nesses 30 anos e o atual estado-da-arte. $\mathrm{O}$ modo como a pesquisa em aquisição da linguagem conduzida no Brasil se inscreve nessa história deverá emergir à medida que essas questões forem tematizadas.

\subsection{Desenvolvimento cognitivo e a representação de relações gramaticais}

Sabe-se que, por volta dos anos 70, o paradigma teórico behaviorista já se havia desgastado ${ }^{9}$. Requeria-se uma teoria de desenvolvimento que desse conta de uma criança cognitivamente ativa e lingüisticamente criativa, em contraposição à criança objeto da ação condicionante do meio antes apresentada pela chamada Teoria Geral da Aprendizagem, que havia dominado a Psicologia Evolutiva norte-americana na primeira metade do século.

O discurso da Epistemologia Genética de Piaget (cf. Piaget, 1976), enfatizando a ação da criança sobre o meio físico, da qual decorreria a

${ }^{9}$ Contribuíram para isso, além dos argumentos de Chomsky, em sua crítica ao Verbal Behavior de Skinner (Chomsky [1959] (1967)), os experimentos clássicos de Bruner, Goodnow \& Austin, 1956 (apud Cromer, 1981), sobre a aquisição de conceitos, e de Berko (1958), sobre o uso produtivo de morfemas flexionais por crianças apresentadas a pseudopalavras. 
construção de estruturas cognitivas fundamentais para todo o tipo de desenvolvimento - os esquemas sensório-motores - apresentava uma alternativa atraente àquela teoria. Dado o seu caráter generalista, i.e. independente de domínio, a teoria de Piaget passou a ser tomada como referência para a caracterização do desenvolvimento cognitivo da criança. A possibilidade de esta teoria de desenvolvimento absorver o desenvolvimento lingüístico (Inhelder, 1980; Morehead \& Morehead, 1974; Sinclair, 1976a; 1976b) ou fornecer um modelo de desenvolvimento capaz de descrever o processo de desenvolvimento no domínio específico da linguagem (Karmiloff-Smith, 1979) gerou diferentes linhas de investigação sobre a aquisição da linguagem no contexto do desenvolvimento da criança.

No primeiro caso, a natureza estrutural da teoria de Piaget facilitou sua aproximação com o tipo de modelo formal de língua apresentado pela Teoria Lingüística, no que este tinha de descritivo. Nessa aproximação, o modelo de língua foi visto como redutível à estrutura lógico-matemática passível de ser abstraída em todos os domínios da cognição, de acordo com a concepção de Piaget (cf. Piaget, 1976; 1980). A gênese da língua ficava, assim, submetida à gênese dessa estrutura cognitiva, qual seja, aos esquemas sensório-motores formados a partir da ação da criança sobre o meio no primeiro ano e meio de vida, dispensando-se, com isso, a necessidade de uma especialização lingüística formulada nos termos de uma GU (embora esse argumento não necessariamente eliminasse a possibilidade de uma programação biológica especificamente lingüística).

Essa linha de investigação mostrou-se, no entanto, equivocada. Por um lado, relações gramaticais não são redutíveis a relações lógico-matemáticas, dado que não há correlação entre medidas de complexidade sintática e morfológica e medidas de desenvolvimento cognitivo definidas nos termos das operações caracterizadas por Piaget. Por outro lado, as previsões de Inhelder (1980) quanto à dependência da língua ao desenvolvimento sensóriomotor não se confirmaram, (cf. Cromer, 1981; Yamada, 1992). De fato, a fragilidade da proposta de Piaget em relação à língua, apoiada numa concepção filogenética insustentável, foi revelada no já citado debate (Piatelli-Palmerini, 1980; 1994).

O estudo da aquisição da linguagem conduzido no Brasil nessa época incorporou a concepção construtivista de desenvolvimento, segundo a qual categorias e estruturas de conhecimento são gradativamente formadas a partir da ação da criança sobre o mundo. Contudo, apenas alguns trabalhos, mais voltados para o desenvolvimento da teoria piagetiana do que para o estudo 
da aquisição da linguagem em si, veicularam visão semelhante à de Sinclair (ver. levantamento de trabalhos da época em Scliar-Cabral, 1976). Na perspectiva, aqui dominante, do chamado sócio-construtivismo, esse tipo de abordagem foi criticado. A ação construtiva da criança na interação verbal é, sob essa perspectiva, vista como direcionada para própria linguagem (de Lemos e Castro Campos, 1978; de Lemos, 1989) (cf. 3.4.1).

Uma outra linha de abordagem para a aquisição da linguagem a partir de uma perspectiva piagetiana tomou forma já no fim da década de 70, com vistas a manter a concepção de desenvolvimento da Epistemologia Genética de Piaget, ao mesmo tempo que eliminando a idéia de reduzir-se a aquisição da linguagem ao desenvolvimento cognitivo (Karmiloff- Smith, 1979). Ao lidar com a questão da aquisição de determinantes, Karmiloff-Smith (1979) apresenta a língua/gem como um espaço-problema para a criança (em sentido equivalente ao de espaço de ação para Piaget). Nesse sentido, esse enfoque aproxima-se da Teoria Lingüística, que apresenta a língua como domínio específico. No entanto, difere das teorias de aquisição da linguagem a ela vinculdas ao supor que a criança terá de atuar cognitivamente sobre o material lingüístico, organizandoo de diferentes formas ao longo do desenvolvimento, levando em conta, inclusive, as possíveis funções de formas lingüísticas no discurso. Nesse ponto, essa abordagem aproxima-se da proposta de de Lemos (cf. 1985), segundo a qual categorias lingüísticas são tomadas como resultado da ação da criança sob a própria linguagem. Difere desta, contudo, ao desconsiderar o papel do interlocutor nesse processo (cf. 3.4.1).

A abordagem cognitiva e funcional (no sentido de relacionado à função da língua no discurso) de Karmiloff-Smith percorreu os anos 80, focalizando, em particular, a aquisição de formas pronominais, vistas como plurifuncionais. $\mathrm{O}$ fato de uma dada forma, como o pronome referencial, admitir mais de uma função discursiva (manter e alterar a referência) apresentaria à criança um problema de aquisição, no mapeamento entre forma e função (Karmiloff-Smith, 1981 ; 1985; 1987). A criança lidaria com esse problema através de um procedimento geral, aplicável a diferentes domínios da cognição, o qual refletiria um modo particular de organização do conhecimento num dado estágio de desenvolvimento cognitivo (Karmiloff-Smith, 1985; 1987). A aquisição da linguagem, coordenada por um desenvolvimento cognitivo mais amplo, passaria por um processo de sucessivas re-descrições (Karmiloff-Smith, 1992).

A proposta de Karmiloff-Smith requer um modelo de língua que inclua a representação das funções discursivas assumidas por uma dada forma. Embora 
tenham sido feitas tentativas nessa direção em vertentes funcionalistas da Linguiística, o tipo de modelo de língua proposto (cf. Kuno, 1987), por não ser comprometido com o objetivo de apresentar uma língua que satisfaça a critérios de aprendibilidade, não pode ser imediatamente incorporado a uma teoria de aquisição da linguagem.

Não é claro, contudo, até que ponto a idéia de se incorporarem representações de natureza discursiva em um modelo de língua é promissora. A habilidade de se conduzir processamento sintático e interpretação semântica no nível da sentença parece estar, até certo ponto, dissociada da habilidade de se conduzir processamento no nível do discurso, como sugerem os déficits que se manifestam de forma diferenciada nessas habilidades (cf. Smith \& Tsimpli, 1995) e a relativa independência no modo como processos sintáticos e discursivos são fisicamente implementados em hemisférios distintos do cérebro (cf. Dennis, 1998; Cohen \& Le Normand, 1998).

No Brasil, o estudo do desenvolvimento de habilidades discursivas tem atraído considerável interesse, tanto no que concerne ao desenvolvimento da produção oral quanto da escrita, (Guimarães, 1994; Soares, 1991; 1997; Uller, 1990). No que diz respeito à referência pronominal, contudo, a idéia de a plurifuncionalidade do pronome referencial constiuir um problema de aquisição da linguagem, no sentido de aquisição de língua, tal como apresentado por Karmiloff-Smith (1981; 1985; 1987), tem sido questionada (Corrêa, 1995c; 1999a, 1999b), a partir de uma perspectiva teórica que incorpora um modelo do processamento do material lingüístico no tratamento de questões relativas à aquisição da linguagem (cf. 4).

\subsection{Relação sintaxe / semântica na aquisição da linguagem}

O estudo da aquisição da linguagem no contexto do desenvolvimento da criança nos anos 70 também colocou em foco a semântica na aquisição de uma língua. $\mathrm{O}$ interesse em aspectos semânticos nessa época pode ser visto, em grande parte, como uma reação à ênfase na sintaxe que havia predominado nos anos 60, com descrições da produção lingüística da criança em termos de gramáticas pivot (Braine, 1963; MacNeill, 1966) e fala telegráfica (cf. Brown, 1973). A pesquisa no âmbito da Lingüística Gerativista vivenciava intenso debate quanto ao modo de situar um componente semântico no modelo de língua e de se formalizarem aspectos semânticos não captados no chamado modelo padrão (i.e. Chomsky, 1965) (cf. Fillmore, 1968; McCawley, 1968; Lakoff, 1971). Isso levou os dissidentes da "autonomia da sintaxe" a constituirem a 
Semântica Gerativa como corrente teórica autônoma. Esses modelos lingüísticos alternativos pareciam oferecer ao estudioso da aquisição da linguagem meios de descrever relações semânticas atribuídas à fala da criança (cf. Schlesinger, 1971; Brown, 1973; Bowerman, 1973). Buscou-se, assim, caracterizar o que as crianças dizem quando começam a produzir enunciados lingüísticos e concebeu-se o método da interpretação rica, através do qual diferentes significados são atribuídos a enunciados aparentemente semelhantes, em função do contexto em que foram produzidos (Bloom, 1970; 1973). A já mencionada influência do pensamento piagetiano no estudo da aquisição da linguagem levou a que se caracterizassem as relações semânticas expressas na fala da criança como expressão da inteligência sensório-motora (Brown, 1973) e, sob a influência da Semântica Gerativa, concebeu-se uma descontinuidade no desenvolvimento lingüístico, com representações inicialmente semânticas, no sentido de temáticas, evoluindo para representações sintáticas no processo de aquisição da língua (cf. Antinucci \& Parisi, 1973; Bowerman, 1973).

A interpretação das relações de sentido expressas pela criança em termos de uma lógica sensório-motora fica, não obstante, comprometida quando se questionam as bases empíricas da teoria de desenvolvimento cognitivo em questão. Com o desenvolvimento de técnicas de experimentação com bebês, como a mensuração do tempo em que o bebê olha para determinado ponto, tem sido possível atribuir à criança uma relação conceptual com o mundo bem mais abstrata do que fazia supor a lógica sensório-motora (cf. Spelke, 1990; 1994). Quanto à hipótese da descontinuidade entre o que seriam relações semânticas e sintáticas, esta não se apresenta satisfatória no tratamento de dados longitudinais e deixa em aberto o modo como uma alteração qualitativa nas representações gramaticais transcorreria (ver Atkinson, 1982 para uma revisão crítica da literatura dessa época).

Os primeiros estudos da aquisição da linguagem conduzidos no Brasil inseriram-se na discussão sobre o tipo de modelo que seria mais adequado na caracterização de estados da competência lingüística da criança ao longo do desenvolvimento. De acordo com as tendências da época, focalizavam aspectos de natureza semântica na aquisição da linguagem e apontavam para limitações do modelo chomskyano de gramática na caracterização daqueles (cf. ScliarCabral (1977), (Albano) Mota Maia (1975), de Lemos (1975)).

A necessidade de se incorporarem elementos semânticos num modelo de língua comprometido com "adequabilidade explanatória" tornara-se 
evidente. No âmbito da Semântica Gerativa, a formalização de relações sintáticas a partir de relações semânticas não se mostrou, contudo, factível, o que promoveu um redirecionamento na pesquisa que evoluiu dessa vertente para a chamada Lingüística Cognitiva (cf. Lakoff,1990). No âmbito do Gerativismo "clássico", soluções formais, tais como a atribuição de uma estrutura argumental a núcleos lexicais (cf.Grimshaw, 1990) e a caracterização de posições estruturalmente definidas para o estabelecimento de relações de co-referência (cf. Chomsky \& Lasnik [1993] em Chomsky, 1995; Reinhart, 1986), têm sido buscadas para que as relações entre sintaxe e semântica possam ser explicitadas.

Atualmente, a hipótese de uma descontinuidade entre categorias sintáticas e semânticas no desenvolvimento lingüístico não mais se apresenta como tal. Questões relativas à descontinuidade encontram-se praticamente restritas a aspectos específicos da morfologia da língua e do léxico (Bowerman, 1982; 1991; Figueira, 1977; 1995; 1999). Em todo o caso, o questionamento em torno de uma possível "prioridade epistemológica" de relações temáticas sobre relações sintáticas geradas no âmbito do estudo da aquisição da linguagem tem retornado à Teoria Lingüística (cf. Pesetsky, 1982 apud Chomsky and Lasnik [1993] em Chomsky, 1995).

Grande parte da dificuldade no tratamento de questões relativas à semântica no estudo da aquisição da linguagem advém da falta de clareza quanto ao que entender por "semântica" quando a linguagem da criança é analisada. Slobin (1985), por exemplo, desenvolve um estudo comparativo da aquisição da linguagem em diferentes línguas, partindo da hipótese de que há universalidade na ordem de aquisição de conceitos e toma tal ordenação como parâmetro de comparação. Diferenças no curso da aquisição de diferentes línguas são vistas como decorrentes de dificuldades no mapeamento entre forma lingüística e função ou conteúdo semântico, cujo desenvolvimento, por ser de natureza cognitiva, seria constante. Assim, se numa dada língua a criança utiliza, por exemplo, a flexão de número, numa dada idade, e em outra língua não o faz, considera-se que há um impedimento formal para a expressão de um conteúdo semântico já incorporado pela criança (cf. Slobin $(1973 ; 1985)$ e Peters (1985) para uma discussão de dificuldades dessa proposta).

Note-se que, nesse tipo de abordagem, prevalece uma concepção "bloomfieldiana" de semântica, entendendo-se por semântico conceitos, intenções, o objeto ou evento da referência, enfim, tudo para o que a língua apresentaria um rótulo. Essa confusão entre semântico, conceitual e referencial 
se faz presente em grande parte da literatura em aquisição e desenvolvimento da linguagem, como assinala Cromer (1981), que chama atenção para uma disitinção entre semântico - relativo à significado na língua e conceptual - no domínio estritamente cognitivo.

Nas últimas décadas, a discussão em torno da relação entre sintaxe e semântica na aquisição da linguagem tem sido conduzida no âmbito de teorias que partem do pressuposto de uma especialização lingüística e que admitem a hipótese da continuidade no que concerne à disponibilidade dos princípios de GU a partir do estado inicial do processo de aquisição de uma primeira língua. Existe uma aparente controvérsia quanto ao papel a ser atribuído à informação de natureza semântica no processo de aquisição da língua, que contrapõe a chamada hipótese do bootstrapping ${ }^{10}$ semântico (Pinker, 1987; 1989) ao chamado bootstrapping sintático ${ }^{11}$ (Gleitman, 1990).

Segundo a hipótese do bootstrapping semântico, a criança seria biologicamente programada para assumir uma correlação entre sintaxe e semântica, ainda que a primeira não seja redutível à segunda, e seria capaz de derivar representações semânticas a partir de informação lexical e contextual. (Pinker, 1987) (o que é posteriormente revisto, para representações conceptuais, requerendo uma mediação lingüística para a formação de representações semânticas (Pinker, 1989)). Tais representações, correlacionadas a padrões sintáticos, desencadeariam de GU as propriedades relevantes para a identificação das relações sintáticas em questão ${ }^{12}$. A hipótese do bootstrapping sintático, por outro lado, remete ao papel da informação sintática relativa a traços de subcategorização na aquisição do significado de verbos e prevê maior importância à informação sintática do que à informação de natureza conceptual na atribuição de sentido a um enunciado pela criança.

Uma série de estudos experimentais tem demonstrado que crianças levam em conta informação sintática ao inferir o significado de enunciados relacionados a uma cena ou situação. Esses resultados têm sido interpretados como evidência de que a aquisição do significado de verbos é direcionada por

${ }^{10}$ Ver nota 4.

${ }^{11}$ Nesse caso, o uso do termo bootstrapping cria um contraponto apenas nominal com o "semântico", dado que os processos a que se referem são de natureza distinta - um remete ao sistema computacional da língua e o outro ao léxico. É apenas em relação ao primeiro que o sentido de auto-desencadeamento de um sistema se aplica (cf. Pinker, 1994).

${ }^{12}$ Esta é uma apresentação simplificada. Para discussão dos pressupostos dessa hipótese e de dificuldades inerentes a ela, ver Pinker (1989). 
informação relativa aos esquemas (frames) sintáticos em que estes se encontram (Gleitman, 1990; Fisher et al., 1994). Fisher et al, 1994, por exemplo, investigaram a influência relativa de restrições de ordem conceptual (uma ação pressupõe um agente causal) e sintática (relativas à transitividade do verbo) no modo como crianças de 3 e 4 anos inferem o significado de verbos inventados utilizados na descrição de situações passíveis de serem interpretadas em termos de relações semânticas distintas, tais como dar/receber, perseguir/ escapar. Verificou-se que a influência de restrições sintáticas é maior do que as de ordem conceptual na atribuição do papel de agente a um NP, pela escolha do verbo utilizado pelas crianças para parafrasear a descrição da cena. Seria, contudo, esse tipo de resultado uma evidência contrária à hipótese do bootstrapping semântico?.

Resultados que apontam para a maior relevância de informação de natureza sintática do que generalizações de ordem conceptual na aquisição do significado de verbos não afetam a tese do bootstrapping semântico. Esta não diz respeito ao modo como o significado de itens lexicais pode ser adquirido e sim ao modo como o sistema computacional da língua (ou subsistemas deste) pode ser operacionalizado ou "inicializado" a partir de representações de ordem semântica. Por outro lado, a proposta de aquisição de significado lexical fundada na sintaxe não exclui o papel da referência a eventos nesse processo, como a leitura de Pinker (Pinker, 1994) faz crer (cf. Gleitman, 1990). Assim, o confronto entre bootstrapping semântico e sintático não se faz pertinente pois cada hipótese diz respeito a um processo distinto. A principal dificuldade da hipótese do bootstrapping sintático diz respeito ao fato de não haver correspondência biunívoca entre padrões sintáticos e relações semânticas de modo a garantir a eficácia do processo para todo o tipo de verbo. No que concerne ao bootstrapping semântico, essa hipótese incorpora a dificuldade de se caracterizar o modo como processos perceptuais dão origem a representações conceptuais e como estas se relacionam com representações semânticas numa dada língua.

De fato, a relação entre representações conceptuais e semânticas apresenta um dos problemas de mais difícil resolução no âmbito de uma teoria semântica/lingüística, sendo recentes as propostas para um tratamento formal integrado dessas relações em nível proposicional e lexical (cf. Jackendoff, 1983; Pustejovsky, 1995). Mas a despeito das dificuldades em prover-se um tratamento formal para essa relação, a articulação entre desenvolvimento conceptual e lingüístico tem sido uma preocupação no estudo da aquisição da linguagem desde sua fase inicial. 
Esta questão foi abordada diretamente por Cromer ((1974)), o qual propôs a chamada Hipótese da Cognição como alternativa ao determinismo lingüístico expresso na chamada hipótese Sapir-Whorf, ainda dominante nos anos 60 . Estudos experimentais com crianças com menos de 1 ano vinham demonstrar a anterioridade de conceitos em relação à sua expressão lingüística (cf. Macnamara, 1977), juntando-se a uma série de evidências que davam suporte ‘aquela hipótese (Cromer (1991)). Contudo, o próprio Cromer apresenta argumentos que gradativamente a relativizam, revisando estudos sobre a aquisição de termos que se distinguem em função da variável [+/- contável] por crianças adquirindo inglês e sobre a aquisição da categoria número, por crianças falantes de inglês e de Yucatec (língua Maia, na qual apenas nomes [animados] admitem plural). O resultados desses estudos evidenciam processos que levam em conta diferenças formais na identificação de categorias semânticas.

Recentemente, estudos sobre a aquisição do léxico - processo que parece tomar forma por volta dos 9 meses de idade (cf. Jusczyk, 1997), têm sugerido que formas lingüísticas (palavras novas) contribuem para que bebês dessa idade categorizem objetos (Waxman, 1994). A possibilidade de formas lingüísticas contribuírem para a aquisição de conceitos foi particularmente aventada por Vygotsky (1962) e é levada em conta em formulações teóricas que atribuem às relações interpessoais que se estabelecem pela linguagem verbal um papel fundamental no estabelecimento de relações semânticas na língua (cf. 3.4).

3.3. A fala dirigida à criança e as condições necessárias à identificação de uma língua

Uma outra vertente de pesquisa aberta no estudo do desenvolvimento da criança a partir da hipótese inatista buscou caracterizar a fala dirigida à criança e verificar o possível efeito da qualidade desta no desenvolvimento lingüístico.

A argumentação que acompanhava a hipótese inatista apresentava os dados lingüísticos primários de que a criança dispõe como constituídos de enunciados fragmentados, cheios de falsos começos e pouco transparentes quanto às possíveis relações gramaticais neles expressas. Psicólogos do desenvolvimento partiram da hipótese de que a fala dirigida a criança (FDC) seria distinta da fala dirigida ao adulto, o que poderia contribuir para facilitar o acesso da criança à língua. Com base numa ampla base de dados de crianças 
adquirindo inglês, e posteriormente, outras línguas, foi constatado que a fala dirigida à criança (FDC) distingue-se da fala dirigida a adultos em função de uma série de variáveis, tais como, complexidade sintática (medida em termos de número de morfemas por enunciado, número de orações encaixadas, número de orações subordinadas em posição inicial, etc.), boa-formação (caracterizada em função da presença hesitações, falsos começos, pausas dentro de constituintes, etc, nos enunciados), formas lexicais (formas próprias, com reduplicação de sílabas), tornando-se aparentemente mais simples, bem formada e redundante do que a fala entre adultos (cf. Kaye, 1980 apud Ingran, 1989; Snow, 1986). De um ponto de vista fonético, verificou-se que a FDC apresenta caracteristicamente um alto pitch, um maior leque de freqüências e entonação mais variada do que a fala dirigida ao adulto (cf. Ingram, 1989). Estudos realizados na cultura ocidental revelam, ainda, que desde cedo (registros a partir dos 3 meses) a fala dirigida ao bebê tende a referir-se a ele e, a partir do momento em que seu foco de atenção possa ser dirigido, a objetos ou atividades do seu interesse (cf. Snow, 1986).

Tais resultados claramente contradiziam o que era pressuposto por Chomsky (1964 apud Allen \& van Buren, 1971)). Contudo, como admite Snow (1986), estas evidências só poderiam eliminar a necessidade de uma predisposição específica para a aquisição de línguas caso fosse demonstrado que outras espécies, comparado o nível de inteligência, seriam bem sucedidas na tarefa de adquirir uma língua humana, mediante dados simplificados, o que claramente não é o caso (cf. Aitchison,1976). Além disso, a existência desse resgistro especial não implica que o uso deste seja uma condição necessária para a aquisição de uma língua.

Ingram (1989) apresenta um sumário de estudos etnográficos que revelam diferentes atitudes culturais em relação ao bebê que fazem com que não lhe seja dirigida a palavra até que ele fale, seja como forma de proteger sua alma, entre os Quiché da Guatemala, porque tal atitude iria de encontro a convenções de etiqueta, entre os Samoanos da Nova Guiné, porque bebês ainda "não são humanos", entre os Javaneses, ou simplesmente por provocarem ciúme entre os Mundugumor. Estudos de casos de crianças que adquiriram uma primeira língua em condições socialmente precárias também sugerem que a FDC não é condição necessária para a aquisição de uma língua materna. Skuse (1993) relata uma série de casos de crianças submetidas a situações extremas de isolamento ou abandono na primeira e média infância, as quais, uma vez integradas socialmente, foram capazes de adquir uma língua materna. O mais impressionante é o caso de Isabelle, que viveu isolada com uma mãe surda- 
muda até os 6 anos e, segundo o relato, após uma semana de contato com língua oral ${ }^{13}$, começou a vocalizar, tornando-se, em um ano, capaz de aprender a ler e a escrever. Crianças com audição normal, cujos pais são surdos, não adquirem, contudo, a língua da comunidade mais ampla assistindo`a televisão ou presenciando situações eventuais de interlocução oral em que não estejam envolvidas (Sachs, Bard \& Jonhson, 1981). É possível, pois, que a imersão da criança num particular modo de interação lingüística (oral ou de sinais) seja condição crucial para que seu potencial lingüístico seja ativado e não necessariamente seu contato com um registro com as propriedades da FDC.

A qualidade da interação entre a criança e o adulto pode, não obstante, afetar o desenvolvimento linguístico. Estudos de casos evidenciam que crianças cujos interlocutores não costumam expandir ou manter o tópico do diálogo, tendem a produzir uma fala repetitiva, pouco informativa e com problemas de articulação (Lieven, 1978 apud Snow, 1986). Parece, pois, que as expansões são de grande relevância para o desenvolvimento do potencial expressivo da linguagem embora a prática de o adulto expandir os enunciados de crianças possa não ser essencial para a que a criança lide com o modo de operação da língua e identifique sua propriedades organizacionais básicas. (cf. Ochs \& Sheiffelin, 1984; Snow, 1986).

No Brasil, o estudo da FDC não teve maior expressão ${ }^{14}$. O que atraiu considerável atenção de pesquisadores no país foi o diálogo, visto como meio de inserção da criança na língua, no discurso e como forma de torná-la sujeito da linguagem.

\subsection{A interação e o diálogo na aquisição da linguagem}

Ainda na década de 70, a interação comunicativa e o diálogo passaram a atrair atenção no estudo do desenvolvimento lingüístico. Halliday (1975) apresentava uma análise funcionalista das emissões vocais de seu filho Nigel, numa fase dita "pré-lingüística", segundo a qual uma série de intenções identificadas com funções da linguagem são atribuídas à criança. Bates (1976) concebe uma origem pragmática para a linguagem, introduzindo uma concepção teórica que tem como principal problema dar conta da descontinuidade entre o que seriam categorias de natureza comunicativa e categorias gramaticais no

\footnotetext{
${ }^{13}$ Não consta do relato que o registro comumente utilizado com bebês tenha sido adotado. ${ }^{14}$ Apenas duas referências, remetendo a dissertações de mestrado conduzidas na PUC-Rio, ainda nos anos 70 , foram encontradas no levantamento dos estudos da aquisição da linguagem no Brasil apresentado em Scliar-Cabral, 1989.
} 
desenvolvimento (ver também Bates, Camaoni, Volterra,1979; Bates \& MacWhinney, 1982). Bruner(1983) ${ }^{15}$., parafraseando Austin (1962), perguntase "how to get things done with words?" e introduz o problema de como a criança desenvolve a habilidade de produzir enunciados pragmaticamente efetivos num dado contexto.

A proposta de Bruner, ao contrário das demais, não atribui uma origem pragmática para língua. Segundo ele, jogos interativos entre mãe (adulto) e criança apresentariam a esta esquemas interacionais necessários ao desenvolvimento de habilidades lingüísticas de caráter pragmático tais como a habilidade de solicitar, de estabelecer referência, dentre outras (Bruner, id. ibid.). Bruner leva em conta o problema lógico apresentado pela Teoria Lingüística ao supor a necessidade de um "LAD” (cf. 2.1.1). Considera, contudo, necessário introduzir o conceito de LASS (Language Acquisition Support System) numa teoria do desenvolvimento lingüístico. O LASS consistiria de um esquema (format) interacional, inicialmente sob o controle do adulto, o qual seria necessário para que o LAD fosse posto em funcionamento. Assim, `a medida que a criança fosse inserida num modo de agir por meio da linguagem, poria em funcionamento um aparato para aquisição da língua em questão.

O pensamento de Bruner tornou-se influente, particularmente no contexto europeu $^{16}$ (Camaioni, 1979; McShane,1980). A concepção de jogos interacionais levaria à formulação dos conceitos de especularidade, complementaridade e reciprocidade para caracterizar a interação entre mãe (adulto) e criança, a partir dos enunciados de uma palavra (Camaioni,1979). Esses conceitos foram resignificados por de Lemos (cf. de Lemos, 1989), ao aproximá-los da teoria construtivista de desenvolvimento cognitivo de Piaget, conciliada à perspectiva de Vygotsky, no que concerne ao papel da interação social por meio da língua nesse desenvolvimento (cf. 3.4.1)

A linha de pesquisa iniciada por de Lemos no Brasil tem sido identificada como sócio-interacionismo ou sócio-construtivismo ${ }^{17}$. Essa linha desenvolveuse com alunos e colaboradores a partir do projeto Aquisição da Linguagem (cf. 3) que teve início em 1976 (Castro Campos, 1983; 1992; de Lemos, 1981;

${ }^{15} \mathrm{O}$ livro a que essa referência remete foi editado a partir de uma coletânea de artigos da dé cada de 70 .

${ }^{16} \mathrm{Na}$ década de 70 Bruner passou um período na Universidade de Oxford, onde entrou em contato com a Filosofia da Linguagem.

${ }^{17}$ Ver uma retrospectiva de seu percurso nas duas décadas precedentes em de Lemos (1989)

e do direcionamento que esta tomou nos últimos anos em de Lemos (1999). 
1886 a, 1986 b 1989; Figueira, 1977; 1985; Gebara (Scarpa), 1978; 1985; Lier-deVito, 1983; 1994; Mota Maia (Albano), ${ }^{18}$ 1986, Perroni Simões, 1977; 1978; 1991; Scarpa, 1990). O sócio-interacionismo/construtivismo apresenta-se como a abordagem mais característica do estudo da aquisição da linguagem conduzido no Brasil até recentemente. Cabe, pois, caracterizar essa proposta, relacionando-a com o problema da aquisição da linguagem tal como apresentado pela Teoria Lingüística e abordado no âmbito do estudo do desenvolvimento, ainda que correndo-se o risco de não captar de forma precisa todas as suas implicações.

\subsubsection{A concepção sócio-construtivista de aquisição da linguagem}

A proposta sócio-interacionista/construtivista de de Lemos compartilha com Bruner a idéia de que esquemas interacionais servem como meio para introduzir a criança na língua. Diferentemente de Bruner, contudo, a proposta de de Lemos não vem complementar a concepção do problema "aquisição da linguagem", tal como formulado na Teoria Lingüística, voltando-se para o desenvolvimento pragmático. O sócio-interacionismo/construtivismo identifica-se com correntes antagônicas à idéia de inatismo no estudo do desenvolvimento da criança (cf. de Lemos, 1986a), embora não submeta o desenvolvimento lingüístico a um cronograma regido por um desenvolvimento cognitivo mais amplo, nem atribua uma origem pragmática para a língua. Colocase, pois, no extremo oposto da hipótese que orienta a Teoria Lingüística, no que concerne ao quanto de informação acerca das propriedades do sistema comum às diferentes línguas estaria accessível à criança no estado inicial da aquisição da linguagem, e distancia-se das principais abordagens para a aquisição da linguagem no estudo do desenvolvimento. Enquanto a Teoria Lingüística pressupõe alto grau de determinação para a forma das línguas humanas a partir do estado inicial do processo, a proposta sócio-construtivista assume um alto grau de indeterminação. Segundo essa visão, categorias fundamentais para o sistema lingüístico, tais como Nome e Verbo, não estariam accessíveis para a análise e para a produção da fala pela criança. Teriam de ser construídas ao longo do desenvolvimento, num processo dependente da interação com um adulto (alguém que domina a língua).

A indeterminação atribuída ao estado inicial do desenvolvimento acarreta uma dificuldade metodológica na análise da fala da criança, que torna-se objeto de precupação nessa proposta (de Lemos, 1986b. 1989, 1999; Scollon, 1979).

\footnotetext{
${ }^{18}$ Para um redirecionamento teórico ver Albano, 1987.
} 
Os enunciados produzidos pela criança, numa fase inicial do processo de aquisição da língua, não seriam analisáveis em termos de categorias lingüísticas, dado que as mesmas não estariam disponíveis no início desse processo. Tais enunciados corresponderiam a fragmentos não analisados, tomados da fala do adulto, numa espécie de imitação deferida ${ }^{19}$ (ver também Peters, 1985). A solução apresentada para essa dificuldade metodológica seria tomar o diálogo e não a sentença como unidade de análise (de Lemos, 1986b, 1989; 1999; Scollon, 1979). Nesse quadro, o principal problema teórico consiste em explicar de que modo a criança analisaria as unidades não necessariamente lingüísticas tomadas da fala do adulto de modo a compor unidades lingüísticas em um sistema produtivo. O diálogo é tomado como meio através do qual o processo de construção da língua se realiza a partir de tais fragmentos, assumindo assim uma relevância tanto metodológica quando teórica no estudo da aquisição da linguagem .

O processo de aquisição da linguagem através do diálogo pode ser entendido de duas formas: como um procedimento de produção através do qual criança e interlocutor compõem, conjuntamente, um enunciado "lingüístico", e como processo ontogenético, de construção de categorias lingüísticas. No primeiro caso, fragmentos (equivalentes ao que seriam palavras, sintagmas ou sentenças na fala do adulto) produzidos, em turnos, pela criança e pelo adulto, dariam origem a um enunciado com uma espécie de sintaxe vertical, tal como caracterizada por Scollon (1979) (cf. de Lemos, 1981). Essa relação dialógica teria como propriedades a especularidade (o adulto espelhando o enunciado da criança, parafraseando-o com a estrutura, o sentido e a intenção que atribui a ele); a complementaridade (o adulto ou a criança retomando parte o enunciado do outro e complementando-o) e a reciprocidade (a criança passando a iniciar o diálogo, instaurando o adulto como interlocutor) (cf. de Lemos, 1989). No segundo caso, esse mesmo processo de produção permitiria `a criança agir sobre a fala (sua e do interlocutor) 3/4 condição tomada como necessária para a construção de categorias lingüísticas e o estabelecimento de relações entre elas.

Essa proposta compartilha com Karmiloff-Smith (1979) a concepção de desenvolvimento lingüístico fundada na ação da criança sobre a língua dando origem a processos reoganizacionais. Tal como na teoria de desenvolvimento

\footnotetext{
${ }^{19}$ A expressão "tocando de ouvido", empregada por Albano (1990) (num modo de teorização já distanciado, em muitos aspectos, da proposta sócio-construtivista) para caracterizar um processo que partiria da fala, como ação, para a língua, capta a idéia de indeterminação categorial na apreensão holística da fala do adulto que estaria sujacente `a fala da criança.
} 
lingüístico de Karmiloff-Smith, a concepção de língua subjacente à proposta sócio-interacionista/construtivista não é explicitada. Aos processos reorganizacionais é, não obstante, atribuído um caráter metafórico e metonímico (de Lemos, 1992). Isso sugere que a concepção de língua intuída na proposta sócio-interacionista fundamenta-se em relações de caráter analógico.

Parece, pois, haver uma incompatibilidade entre a concepção de língua subjacente à proposta sócio-interacionista/construtivista e o modelo de língua apresentado pela Teoria Lingüística. Enquanto esse último incorpora um mecanismo gerativo, de caráter essencialmente modular, no qual categorias lexicais, definidas a partir de traços, funcionam como primitivos, a concepção de língua aparentemente intuída na proposta sócio-interacionista parece apresentar a propriedade de isotropia ${ }^{20}$ e o caráter Quineriano ${ }^{21}$, com que Fodor (1983) caracteriza os sistemas centrais da mente - sistemas cognitivos que atuariam em qualquer domínio da cognição e que lidariam com informação proveniente de todo o tipo de fonte, em contraposição aos sistemas modulares. Assim sendo, diferentes objetos parecem estar envolvidos quando a aquisição da linguagem é abordada do ponto de vista da Teoria Lingüística e do ponto de vista da proposta sócio-interacionista. Uma questão teórica que se apresenta é se o objeto língua, tal como intuído nessa proposta, uma vez formalizado, atenderia a condições de aprendibilidade que garantiriam a aquisição de uma língua materna, levando em conta os procedimentos de aprendizagem nela

\footnotetext{
${ }^{20}$ Isotropia diz respeito à qualidade daquilo que apresenta as mesmas propriedades físicas em todas as direções. No sentido com que o termo é incorporado ao texto de Fodor (1983), diz respeito à propriedade da "confirmação" de uma hipótese, extraída de qualquer tipo de evidência, seja empírica ou demonstrativa. Fodor considera que a capacidade geral de resolver problemas é isotrópica e que a isotropia cognitiva pode ser melhor identificada no contexto de descobertas do que no de verificação de hipóteses, pois diz respeito à transferência de informação entre domínios cognitivos, a qual encontraria sua forma mais pura no raciocínio analógico.

${ }^{21} \mathrm{O}$ adjetivo Quineriano remete a Willard Quine, filósofo de origem empirista, muito influente no âmbito da Filosofia da Mente desde a década de 50. Com propostas que abalaram os cânones da Filosofia, como a da dissolução da distinção entre proposições analíticas e sintéticas, assumiu posturas polêmicas no que se refere à Semântica e à relação entre o domínio físico e o mental. O adjetivo usado por Fodor parece remeter às considerações de Quine sobre crenças, desejos e intenções, cuja relação com o comportamento manifesto é vista como indireta, dependente da totalidade do indivíduo, o que o leva a sugerir que as bases de uma interpretação psicológica não são redutíveis a um conjunto de regras ou princípios. Na visão de Quine, tanto uma descrição psicológica quanto a tradução são indeterminadas, de forma que não há como avaliar, em última análise, o quão corretas são. O conceito de empatia viria caracterizar o modo como tal indeterminação não acarretaria dificuldades de entendimento na prática (cf. Hookway (1994) e refências aí contidas).
} 
caracterizados.

Existem ainda outras diferenças que distinguem o estado estável ou final do processo de aquisição apresentado pela Teoria Linguística do que é tomado como resultado do desenvolvimento na concepção sócio-interacionista. Nessa concepção, a aquisição da linguagem tem como produto não apenas uma língua internalizada mas um sujeito psicológico, constituído pela linguagem, considerado a partir de uma perspectiva epistemológica segundo a qual sujeito e objeto definem-se mutuamente. A aquisição da linguagem teria, assim, no diálogo, não apenas as condições tidas como necessárias para a construção de uma língua mas as condições essenciais para o estabelecimento das relações intersubjetivas das quais emergeria a criança como sujeito da linguagem. Daí o interlocutor ser usualmente apresentado, nos trabalhos dessa linha, como o "Outro", ou seja, como representante da alteridade numa relação inter-subjetiva (cf. de Lemos, 1986 a; Lier-de-Vito \& Arantes, 1998; de Castro, 1998).Nesse aspecto, a proposta sócio-interacionista aproxima-se, inicialmente, do pensamento de Vygotsky (1962) (cf. de Lemos, 1989) e, posteriormente da Psicanálise e da Análise do Discurso (cf. de Lemos, 1999a; de Lemos, 1999a).

De Vygotsky, o sócio-interacionismo buscou incorporar o papel atribuído à lingua, entidade que, por ser socialmente compartilhada, ao mesmo tempo que é instrumental na aquisição do conhecimento, introduz a criança no curso de um desenvolvimento sócio-histórico. Uma retomada ao pensamento de Vygotsky pode, não obstante, prover um meio de aproximar-se uma concepção sócio-construtivista de aquisição da linguagem de hipóteses que supõem um maior grau de determinação quanto à forma das línguas, a partir do estado inicial do processo de aquisição.

Vygotsky (1962) atribui à linguagem verbal, ou seja, à língua realizada como forma de expressão no discurso, um papel central no desenvolvimento cognitivo. A criança, de posse da língua como instrumento, desenvolveria o que é chamado de "pensamento verbal" - atividade mental que, ao tornar-se consciente ou deliberada no planejamento de ações voltadas à solução de uma tarefa cognitiva qualquer, necessita de uma linguagem de apoio. Vygostky enfatiza que esse "pensamento verbal", em contraposição à fala, não seria inato e sim determinado socio-historiamente. Assim, ao estabelecer distinção entre pensamento verbal e fala, Vygotsky atribui um caráter socio-histórico ao primeiro e biológico a esta última ${ }^{22}$.

A mediação exercida pela língua na aquisição de conceitos e do discurso organizado no desenvolvimento do pensamento lógico é vista como o papel 
crucial assumido por fatores sócio-históricos no desenvolvimento cognitivo. A ação de agentes sociais nesse desenvolvimento seria, não obstante, restringida pelo cronograma maturacional da criança. Apenas estando a criança numa “zona de desenvolvimento iminente" poderia sua interação com o adulto acelerar a descoberta da solução para uma dada situação-problema na dinâmica do processo evolutivo.

Aproximar a proposta sócio-construtivista para a aquisição aquisição da linguagem do pensamento de Vygotsky requer transportar o papel mediador da linguagem para atuar na aquisição da própria línguagem (cf. de Lemos, 1986b). Faz-se necessário, contudo, distinguir os diferentes significados do termo linguagem nesse contexto para facilitar o entendimento das diferentes dimensões dessa proposta. Assim, a linguagem, como língua realizada no discurso incorpora todo o significado sócio-histórico que lhe possa ser atribuído. Esta realização viria a interferir na aquisição da linguagem entendida como língua (equivalente a uma língua interna construída), ao mesmo tempo que promoveria a constituição da criança como sujeito da linguagem, entendia como forma de expressão.

De acordo com a concepção de Vygotsky, uma interferência dessa natureza estaria condicionada ao cronograma de desenvolvimento da criança. Uma vez que a interferência no desenvolvimento cognitivo estaria submetida ao cronograma deste, uma atuação da linguagem no domínio da língua, teria de obedecer o cronograma dessa última. A incorporação do pensamento de Vygostsky em uma teoria da aquisição da linguagem parece, pois, pressupor uma concepção de língua fundada numa programação biológica específica responsável por tal cronograma de desenvolvimento. Logo, a incorporação do pensamento de Vygotsky a uma teoria de aquisição da linguagem não parece requerer a hipótese de indeterminação subjacente à proposta sóciointeracionista.

Observa-se que as dificuldades de se assumir total indeterminação no processo de aquisição da linguagem têm sido apontadas e levadas em conta no âmbito de teorias de incorporam processos construtivos ao desenvolvimento lingüístico. Peters (1985), por exemplo, assinala que qualquer processo de reestruturação pressupõe a percepção de determinadas

\footnotetext{
${ }^{22}$ A seguinte citação pode ilustrar esse ponto:“O pensamento verbal não é uma forma de comportamento inata e sim determinada por processos histórico-culturais cujas propriedades específicas e leis não podem ser encontradas nas formas naturais do pensamento e da fala." Vygotsky (1962, p.51, Trad. LMSC)
} 
propriedades do sinal acústico como passíveis de serem lingüisticamente relevantes. Scarpa (1999) considera o papel da prosódia promovendo um bootstrapping fonológico em relação a um modelo de GU inspirado na Teoria da Otimidade. Albano, que vem desenvolvendo uma linha de pesquisa inserida na Teoria da $A c ̧ a ̃ o^{23}$, com vistas a caracterizar um continuum evolutivo da sensório-motricidade à cognição, fundado no conceito de gesto articulatório (cf. Albano, 1999), considera a possibilidade de conciliação dessa perspectiva com um conceito de GU, tal como apresentado naquela teoria (Albano, comunicação pessoal).

A idéia de processos construtivos pode ser, portanto, compatibilizada com hipóteses que pressuponham restrições à forma de línguas a serem adquiridas a partir de informação disponível no estado inicial do processo ou das propriedades de sistemas perceptuais (articulatórios) dedicados ao processamento lingüístico. Note-se que o processo de aquisição concebido na proposta sócio-interacionista toma a criança a partir do momento em que esta fala. Muito do processo de aquisição de uma língua transcorre, contudo, antes que produção da fala se realize (cf. 4).

Grande parte dos estudos em aquisição da linguagem orientados pela perspectiva sócio-interacionista volta-se para aspectos do desenvolvimento relativos ao léxico, à semântica ou para habilidades de natureza discursiva (cf. de Castro (Campos), 1983; 1992; Figueira, 1977; 1985; 1995; 1999; Perroni Simões, 1977; 1978; 1986; 1991). É possível, pois, que os processos de desenvolvimento caracterizados nessa proposta, ainda que possam não ser necessários à construção de primitivos lingüísticos, correspondam a processos requeridos em domínios específicos da linguagem.

4. Procedimentos de aquisição e habilidades de processamento lingüístico de crianças

Um requisito fundamental de uma teoria da aquisição da linguagem consiste em prover um modelo da dinâmica desse processo, ou seja, dos

${ }^{23}$ Nos termos da Teoria da Ação (cf. Kugler \& Turvey 1987 apud Albano, 1999), uma ação pode ser definida como uma gama de movimentos por meio dos quais uma conduta motora se realiza, o que facilita um tratamento quantitativo para o desenvolvimento. No âmbito da Fonética, essa abordagem tem facilitado a caracterização de gesto articulatório, fundamentada em princípios da Dinâmica, a partir da qual a continuidade do desenvolvimento fonético/fonológico é explicitada (Albano, 1999). A concepção de gesto articulatório também orienta o trabalho de Teixeira, sobre o desenvolvimento fonológico (cf. Teixeira \& Davis, 1999). 
procedimentos através dos quais a aquisição de uma língua qualquer se realiza. Desde os anos 70, a Psicologia Cognitiva tem buscado caracterizar procedimentos de aquisição de uma língua materna que podem pressupor maior ou menor grau de determinação quanto à forma das línguas humanas. Diferentemente das teorias de base interacionista acima apresentadas, os procedimentos de aquisição são concebidos a partir de um modelo do processamento do material lingüístico pela criança.

No artigo clássico de 1970, Bever concebe estratégias perceptuais para a aquisição de uma primeira língua que visam a extrair sentido de enunciados lingüísticos a partir de generalizações quanto à forma superficial (ou configuração) dos mesmos. Tais estratégias eram vistas como submetidas a restrições gerais à percepção e, nesse ponto, eram situadas as bases cognitivas para a aquisição da linguagem. A proposta de Bever não se apresentava, contudo, antagônica à Teoria Lingüística, uma vez que as estratégias perceptuais incorporavam uma série de pressupostos gramaticais (tais como a relevância da ordem dos consituintes lingüísticos, a relevância de palavras funcionais) que teriam de ser atribuídos a uma GU. Ao longo dessa década, uma série de estratégias de aquisição foi apresentada (cf. Cromer, 1976). O problema da utilização do conceito de estratégia no estudo da aquisição da linguagem residia, contudo, no fato de, por um lado, confundirem-se estratégias de compreensão (meios de se atribuir sentido a um enunciado) com estratégias de aquisição de língua (cf. Corrêa, 1982; 1986), e, por outro, no fato de a teoria de língua então pressuposta (o modelo padrão (Chomsky, 1965)) requerer a aquisição de regras específicas - concepção que se mostrou improdutiva (cf. 2). Com isso, as estratégias propostas, ainda que dessem conta do padrão de respostas de crianças em tarefas de compreensão, não eram capazes de explicar a dinâmica do processo de aquisição.

Numa linha menos comprometida com a Teoria Lingüística, embora pressupondo uma série de unidades lingüísticas como primitivos, Slobin (1973; 1985) concebeu procedimentos que aquisição de línguas a partir daquilo que enunciados lingüísticos teriam de perceptualmente saliente em qualquer língua e que pudesse ser gramaticalmente relevante. Slobin (1985), partindo de um amplo estudo comparativo entre diferentes línguas, desenvolve a concepção de princípios operacionais universais, formulados em termos de instruções para um mecanismo de aquisição da linguagem. A ausência de uma teoria de língua, por um lado, e de um modelo de processmento lingüístico no qual saliência perceptual pudesse ser caracterizada dificultam, contudo, essa proposta. 
MacWhinney (1987), numa perspectiva menos conciliável com a Teoria Lingüística, apresentou o chamado modelo da competição - modelo probabilístico segundo o qual um mapeamento forma-função é caracterizado, ponderando-se a importância relativa de uma "forma" na língua (tal como a ordem de palavras) e seu custo de processamento. Dados de diferentes línguas serviram de base para sua proposta. Contudo, a falta de respaldo de base experimental para o que é tido como fácil de processar, aliada `a carência de uma teoria de língua, tem como resultado mais um inventário descritivo, baseado em critérios diversificados, do que procedimentos que possam explicar o modo como o processo de aquisição se realiza.

O possível efeito de propriedades distribucionais e contingência semântica foi explorado por Maratsos \& Chalkley (1981), no que se refere à identificação de categorias gramaticais. A proposta de Maratsos \& Chalkney incorpora, implicitamente, uma série de primitivos lingüísticos. Entretanto, esses procedimentos parecem acarretar problemas comuns a procedimentos de aprendizagem indutiva, não satisfazendo, portanto, aos critérios de aprendibilidade requeridos de teorias de aquisição de línguas naturais (ver Pinker, 1987).

Mais recentemente, procedimentos de natureza conexionista têm sido caracterizados para modelar o processo de aquisição (ou de aprendizagem) da língua materna (cf. Plunkett, 1997). Tais procedimentos, de base eminentemente associacionista, são, em princípio, conciliáveis com modelos de cunho probabilístico tais como o de MacWhinney (1987). Modelos probabilísticos ou modelos conexionistas para a aquisição da linguagem requerem, não obstante, uma teoria de língua que seja com eles compatível. A Teoria da Otimidade apresenta-se como uma possível base teórica para tais modelos, muito embora esta pressuponha maior grau de determinação e especificidade de domínio do que procedimentos conexionistas - caracteristicamente independentes de domínio, usualmente pressupõem. No Brasil, uma linha de pesquisa emergente busca uma abordagem conexionista para a aquisição da linguagem (cf. Poerch et al, 1998).

As propostas para procedimentos de aquisição de língua materna concebidas até então partem de um estágio do processo no qual unidades lexicais, morfológicas e sintáticas já são segmentadas. Pode-se dizer, portanto, que lidam com o processo de aquisição da linguagem numa fase avançada, quando comparada com o processamento do material lingüístico que se opera 
até que se possa atribuir à criança a segmentação de tais unidades. Alternativamente, numa abordagem psicolingüística para aquisição da linguagem que também tomou forma nos anos 70, busca-se caracterizar o que a criança processa do sinal acústico (vinculado ou não a outros estímulos que contribuam para a identificação de seu significado) antes de ela emitir enunciados caracteristicamente lingüístico (ver histórico e referências em Mehler \& Dupoux, 1990).

Os estudos da percepção da fala por bebês têm revelado que muito do processo de aquisição da linguagem transcorre antes de a criança atuar linguisticamente por meio da fala. Uma série de resultados sugere a necessidade de uma teoria da aquisição da linguagem incorporar um aparato perceptual altamente especializado para o processamento de línguas que seja posto em funcionamento aos primeiros contatos da criança com uma língua. O recémnascido é, por exemplo, capaz de discriminar melodias de vozes (Aslin, Pisoni, Jusczyk, 1983). Aos 3 meses, bebês orientam-se pela voz da mãe (cf. Locke, 1997). Aos 9 meses reconhecem o padrão fonotático da língua em aquisição (Jusczyk et al, 1994). Aparentemente, capacidades fonéticas discriminatórias que se desenvolvem nos primeiros meses de vida podem ser determinantes de uma "surdez" para distinções que não são fonêmicas na língua materna, o que sugere que a identificação do sistema fonológico pode se realizar antes mesmo de unidades lexicais serem segmentadas (Dupoux, \& Peperkamp, no prelo). Diante dessas capacidades, a necessidade de supor uma programação biológica linguisticamente específica e a possibilidade de um bootstrapping fonológico ou via prosódia têm sido amplamente consideradas (Christophe \& Dupoux, 1997; Scarpa, 1999).

Também no que se refere à sintaxe e ao léxico, cada vez mais o estudo do processo de aquisição da linguagem volta-se para as capacidades de processamento de crianças com idade inferior a dois anos, quando muitas ainda não produzem enunciados de mais de uma palavra. Constata-se, por exemplo, que crianças antes de produzirem linguagem falada são sensíveis `a ordem dos constituintes da língua, distinguindo, em função desta, os papéis de agente e objeto da ação (cf. Hirsh-Pasek \& Golinkoff, 1991). Bebês de 9 meses apresentam-se sensíveis a fronteiras sintagmáticas (Jusczyk et al, 1992) e a unidades lexicais (Waxman, 1994). Aos 11 meses, crianças parecem dintinguir nomes (Myers et al., 1996) e ser sensíveis a morfemas funcionais (Shafer et al., 1998).

No Brasil, o estudo da aquisição da linguagem do ponto de vista do processamento lingüístico tem sido conduzido numa linha de pesquisa que 
teve inicío em meados da década de 80. Numa primeira instância, foi considerada a necessidade de se formular um modelo do estado estável do desenvolvimento lingüístico em termos de processamento, de modo a distinguirem-se problemas de aquisição de língua de problemas de desenvolvimento de habilidades de processamento, dado que ambos podem se confundir nos dados do desempenho lingüístico da criança. (Corrêa, 1986; 1995a; b). Num segundo momento, bucou-se questionar a necessidade de se atribuir `a criança dificuldades na aquisição de formas pronominais, a partir de um modelo em que as funções assumidas por estas formas decorrem de condições de processamento específicas (Corrêa, 1995c; 1999a, b) (cf. 3.2). A proposta de distinguir habilidades dependentes do sistema computacional da língua de habilidades de processamento específicas no desenvolvimento lingüístico orienta o trabalho de Rodrigues (1999) sobre a produção de sentenças coordenadas. Mais recentemente, essa linha tem-se voltado para a identificação de habilidades de processamento no que concerne à percepção de unidades morfológicas e ao estabelecimento de relações de concordância por crianças com idade inferior a dois anos (Corrêa, 1999c; Name, em prep.), assim como `a distinção entre habilidades de processamento lingüístico mais diretamente dependentes do sistema computacional da língua de outras não diretamente a este vinculadas, em portadores de déficits da cognição (de Freitas, a sair).

\section{Um balanço final}

Este artigo buscou apresentar os desenvolvimentos da pesquisa em aquisição da linguagem, compondo um panorama histórico-temático desta segunda metade de século, que permitisse situar a pesquisa em aquisição da linguagem conduzida no Brasil, a partir do momento em que teve início, há quase 30 anos. Nessa retrospectiva, procurou-se levantar o que houve ou há de mais controverso no tratamento desse tema, desde a formulação da chamada hipótese inatista, e identificar os pontos em que essa controvérsia reside, na tentativa de dissolvê-la.

A principal constrovérsia diz respeito ao quanto de informação relativa às propriedades das línguas humanas estaria disponível no estado inicial do processo de aquisição. As principais dificuldades decorrem, por um lado, da falta de um modelo de língua que seja tomado como representativo do estado estável de desenvolvimento na maioria das abordagens para o desenvolvimento lingüístico e, por outro, da necessidade de se explicitar, num modelo de língua, seus modos de articulação com sistemas de desempenho. 
A Teoria Lingüística, na sua principal vertente, encaminha-se hoje para a formulação de um modelo que explicite tal articulação. Com isso, deverá ser possível caracterizar o quanto das restrições `a forma das línguas humanas pode advir do modo de operação desses sistemas. Ao mesmo tempo, modelos alternativos vêm sendo porpostos, o que deverá permitir que se avalie o potencial explanatório de teorias mais ou menos deteminísticas da forma das línguas humanas a partir de uma GU. O estudo da aquisição da linguagem volta-se, por sua vez, mais diretamente para as habilidades de processamento de crianças de tenra idade, o que permite uma melhor caracterização do que há para ser adquirido a partir da produção da fala e do que deve estar.disponível no estado inicial do processo.

A despeito de muitos dos percursos para o estudo da aquisição da linguagem não terem sido produtivos e do caráter insatisfatório de muitas das propostas aqui revisadas, o resultado da pesquisa em aquisição da linguagem nos últimos 30 tem um saldo positivo. Aquele que hoje ingressar no estudo da aquisição da linguagem encontra um campo menos conflituoso e problemas mais bem definidos do que há 20 ou 30 anos.atrás. No que se refere ao estudo da aquisição da linguagem conduzido no Brasil, verifica-se a ampliação do interesse nessa área e uma maior diversificação de abordagens do que nos anos 70. É, entretanto, proporcionalmente pequeno o número de pesquisadores voltados para a aquisição da língua materna, no que concerne à sua identificação, no país.

O estudo da aquisição da linguagem, tomado em sentido amplo, comporta, não obstante, uma série de tópicos não incluídos nessa retrospectiva e que, no Brasil, têm tido maior desenvolvimento. Estes incluem, além do já mencionado estudo do desenvolvimento de habilidades discursivas (cf. 3.2), a aquisição da escrita (Abaurre, 1999), os processos de leitura e o letramento em geral (Grimm-Cabral, 1998; Scliar-Cabral, 1998) assim como a consciência metalingüística e sua relação com a alfabetização (cf. Scliar-Cabral, 1989) ${ }^{24}$. Cada um desses temas abre um campo teórico próprio, não necessariamente integrado ao da aquisição da língua materna, em sentido estrito. Situá-los teoricamente iria muito além do que se poderia requerer nos limites desse artigo. Acredita-se, não obstante, que um posicionamento em relação às questões fundamentais é crucial, qualquer que seja o aspecto do desenvolvimento lingüístico considerado.

REFERÊNCIAS BIBLIOGRÁFICAS:

\footnotetext{
${ }^{24}$ Ver Atas dos Encontros Nacionais de Aquisição da Linguagem para identificação de diferentes linhas de pesquisa.
} 
ABAURRE. M. B. (1999) Horizontes e limites de um programa de investigação em aquisição da escrita. In: Lamprecht, R.R. (org.) Aquisição da Linguagem: Questões e Análises. Porto Alegre: EDIPUCRS.

AITICHISON, J. (1976) The Articulate Mammal. London: Hutchinson

ALBANO, E. (1987) Emergindo da ilusão reducionista em psicolingüística. Cadernos de Estudos Lingüísticos, 12: 4-14

(1999) O gesto articulatório como unidade fônica abstrata: indícios da fala infantil e evidências da fala adulta. In: Lamprecht, R.R. (org.) Aquisição da Linguagem: Questões e Análises. Porto Alegre: EDIPUCRS.

ALLEN, J.P.B. \& P.V. VAN BUREN (1971) Chomsky: Selected Readings. Oxford: OUP.

ANTINUCCI, F. \& D. PARISI (1973) Early language acquisition: a model and some data. In: C.A. Ferguson \& D.I.Slobin (eds.) Studies of Child Language Development. New York: Holt, Reinehart \& Winston.

ASLIN, R.N., D.B. PISONI, P.W. JUSCZYK (1983) Auditory development in speech perception in infancy. In: M. Haith \& J. Campos (eds.) Carmichael's Handbook of Child Psychology: Infancy and Developmental Psychobiology. New York: John Wiley \& Sons.

ATIKINSON, M. (1982) Explanations in the Study of Child Language Development. Cambridge: CUP.

AUSTIN, J. (1962) How to do things with words. Oxford: OUP.

BATES, E. (1976) Language and Context: The Acquistion of Pragmatics. New York: Academic Press.

BATES, E., L. CAMAIONI \& V. VOLTERRA (1979) The acquisition of performatives prior to speech. In: E. Ochs \& B.B. Scheffehn (eds.) Developmental Pragmatics. New York: Academic Press.

BATES, E. \& B. MACWHINNEY (1982) Functionalist approaches to grammar. In: E. Wanner \& L. Gleitman (eds.) Language Acquisition: The State of the Art. New York: CUP.

BELLUGI, U., S. MARKS, A. BIHRLE \& H. SABO (1993) Dissociation between language and cognitive functions in Williams syndrome. In: D. Bishop \& K. Mogford (eds.) Language Development in Exceptional Circurnstances. Hove: Lawrence Erlbaum.

BERKO, J. (1958) The child's learning of English morphology. Word, 14: 150177.

BEVER, T.G. (1970a) The cognitive basis for linguistic structures. In: J. R. Hayes (ed.) Cognition and the Development of Language. New York: John Wiley \& Sons. (1970b) The influence of speech performance on linguistic structure. 
In: G. Flores d' Arcais \& W.J.M. Levelt. (eds.) Advances in Psycholinguistics. Amsterdam: North Holland.

BISHOP, D.V. M. (1998) Uncommon Understanding: Development \& Disorders of Language Comprehension in Children. Hove: Psychology Press.

BLOOM, L. (1970) Language Development: Form and Function in Emerging Grammars. Cambridge, Mass: MIT Press.

(1973) One Word at a Time. The Hague: Mouton.

BLUMENTHAL, L. (1970) Language \& Psychology. New York: John Wiley \& Sons.

BORER, H. \& K. WEXLER (1987) The maturation of syntax. In: T. Roeper \& E.Williams (ed) Parameter-setting in Language Acquisition. Dordrecht: Reidel.

BOWERMAN, M. (1973) Early Syntactic Development: A Cross-linguistic Study, with special reference to Finnish. Cambridge: CUP.

(1982) Reorganizational processes in lexical and syntactic development. In: E. Wanner \& L. Gleitman (eds.) Language Acquisition: The State of the Art. New York: CUP

(1985) What shapes children's grammar?. In: D.I. Slobin (ed.) The Crosslinguistic Study of Language Acquisition, vol.2: Theoretical Issues. Hillsdale, N. J.: Lawrence Erlbaum.

BRAINE, M.D.S. (1963) The ontogeny of syntactical phrase structure: the first phase. Language, 39: 1-13.

BROWN, R. (1973) A First Language: The Earlier Stages. Harmondsworth: Penguin Books.

BRUNER, J. S. (1983) Child's Talk: Learning to Use Language. Oxford: OUP.

CAMAIONI, L. (1979) Child-adult and child-child conversations: an interactional approach. In E. Ochs \& B.B. Scheffelin (eds.) Developmental Pragmatics. New York: Academic Press.

CHOMSKY, N. [1959] Review of Skinner's Verbal Behavior. In: L.A. Jakobovits \& M.S. Miron (eds.) (1967) Readings in the Psychology of Language. Englewood Cliffs, N. J., Prentice Hall.

(1965) Aspects of the Theory of Syntax. Cambridge, Mass.: The MIT Press.

(1981) Lectures on Government and Binding. Dordrecht: Foris. (1986) Knowledge of Language. New York: Praeger. (1995) The Minimalist Program. Cambridge, Mass: The MIT Press. (1997) New Horizons in the Study of Language. D.E.L.T.A., 13. Edição Especial: Chomsky no Brasil: 1-20.

CHRISTOPHE, A. \& E. DUPOUX (1996) Bootstrapping lexical acquisition: the role of prosodic structure. The Linguistic Review, 13: 383-412. 
CLARK, E. (1993) The Lexicon in Acquisition. Cambridge: CUP.

CLEMENTS, G.N. \& E. HUME (1995) The Internal Organization of Speech Sounds. In: Goldsmith, J. (ed) The Handbook of Phonological Theory. Oxford: Blackwell.

COHEN, H. \& M.T. LE NORMAND (1998) Language development in children with simple-parietal left-hemisphere epilepsy. Brain \& Language, 64: 409-422.

CORREA, L. M. S. (1982) Strategies in the acquistion of relative clauses. In: J. Aitichison \& N. Harvey (eds.) Working Papers of the London Psycholinguistics Research Group, 4: 40-56.

(1986) On the comprehension of relative clauses: A developmental study with reference to Portuguese. Unpublished PhD. Dissertation. University of London.

(1995a) An alternative account of children's comprehension of relative clauses. Journal of Psycholinguistic Research., 24 (3): 183-203.

(1995b) The relative difficulty of children's comprehension of relative clauses: A procedural account. In: K.E. Nelson \& Z. Réger (eds.) Children's Language, 8 Hillsdale, N.J.: Lawrence Erlbaun.

(1995c) A plurifuncionalidade do pronome no desenvolvimento lingüístico reconsiderada. Cadernos de Estudos Lingüísticos, 29: 153162.

(1996) Dificuldades e potencialidades do uso do método experimental no estudo da aquisição da linguagem. In: M.F.P. de Castro (org.) $O$ Método e o Dado no Estudo da Linguagem. Campinas: Ed. da UNICAMP. (1999a) A produção de sentenças no discurso e a questão da referência pronominal na aquisição da linguagem recolocada. In: L. G. Cabral \& J. Morais (orgs.) Investigando a Linguagem: Ensaios em homenagem a Leonor Scliar-Cabral. Florianópolis: Ed. Mulheres.

(1999b) Self-correction in the establishment of pronominal reference and the thematic subject strategy reconsidered. Trabalho apresentado no VIII International Congress for the Study of Child Language, San Sebastian. 12-16 de julho.

(1999c) Aspectos do processamento da concordância de gênero. Trabalho apresentado no I Workshop Brasileiro Internacional sobre Processamento de Linguagens, Florianópolis, 16-17 de novembro..

CROMER, R. F. (1974) The development of language and cognition: The Cognition Hypothesis. In: R. F. Cromer (1991) Language and Thought in Normal and Handcapped Children. Oxford: OUP (Obras reunidas, edição póstuma). (1976) Developmental strategies for language. Id. ibid. 
(1981) Reconceptualizaing Language Acquisition and Cognitive Develpment. Id. Ibid.

(1991) The Cognition Hypothesis of language acquisition? Id. ibid.

CULICOVER, P. (1976) Syntax. New York: Academic Press.

CURTISS, S. (1981) Dissociations between language and cognition: cases and implications. Journal of Autism and developmental disorders, 11: $15-20$.

DE CASTRO (CAMPOS), M.F. P. (1983) Processos dialógicos e construção de inferências e justificativas na aquisição da linguagem. Tese de doutorado inédita. UNICAMP.

(1992) Aprendendo a Argumentar: Um Momento da Construção da Linguagem. Campinas: Editora da UNICAMP.

(1998) Sobre a interpretação e os efeitos da fala da criança. Letras de Hoje, 112. Atas do IV Encontro Nacional sobre Aquisição da Linguagem. Porto Alegre: 1997.

DE FREITAS, M. C. (em prep) Avaliação das habilidades lingüísticas de portadores de Síndrome de Willians. Dissertação de Mestrado, PUC-Rio.

DE LEMOS, C.T. G. (1975) The use of ser e estar with particular reference to child language acqusition in Brazilian Potuguese. Unpublished PhD. Dissertation. University of Edinburgh.

(1981) Interactional processes and the child's construction of language. In: W. Deutsch (ed.) The Child's construction of language. London: Academic Press.

(1986a) Sobre aquisição de linguagem e seu dilema (pecado) original. In: J. M. Meisel (ed.) Aquisición de lenguaje /Aquisição da linguagem. Frankfurt: Vervuert.

(1986b) A sintaxe no espelho. Cadernos de Estudos Lingüísticos,10: 5-15.

(1989) Uma abordagem socio-constutivista da aquisição da linguagem: um percurso e muitas questões. Anais do I Encontro Nacional de Aquisição da Linguagem, CEAAL-PUC-RS.

(1992) Los processos metafóricos y metomínicos como mecanismos de cambio. Substratum, 1.1:121-135.

(1999a) Tendências de uma Aquisição da Linguagem Brasileira: Sobre o Interacionismo. Letras deHoje, Volume especial.

(1999b) A criança com(o) ponto de interrogação. In: Lamprecht, R.R. (org.) Aquisição da Linguagem: Questões e Análises. Porto Alegre: EDIPUCRS.

DE LEMOS, C.T. G. \& M. F. de CASTRO CAMPOS (1978) Algumas observações sobre a utilização do modelo piagetiano em recentes estudos 
de aquisição da linguagem. Cadernos de Estudos Lingüísticos, 1: 51-63. DENNIS, M. (1998) Discourse in Children with Neurodevelopmental Disorder, Early Focal Brain Injury, or Childhood Acquired Brain Injury. Brain and Language, 61: 305-307.

DUPOUX, E. \& S. PEPERKAMP (no prelo) Fossil markers of language development: phonological 'deafnesses' in afult speech processing. In: B.Laks and J. Durand (eds.) Cognitive Phonology. Oxford: Oxford University Press.

FELIX, S. W. (1992) Language acquisition as a maturational process. In J. Weissenborn, H. Goodlluck \& T. Roeper (eds.) Theoretical issues in language acquisition. Hillsdale: N. J. Lawrence Erlbaum.

FERNALD, A. (1985) Four-month-old infants prefer to listen to motherese. Infant Behavior and Development, 7: 19-25.

FIGUEIRA, R.A. (1977) Áreas de dificuldade na aquisição do léxico pela criança. Anais do II Encontro Nacional de Lingüística. PUC-Rio: 44-47.

(1985) Causatividade: um estudo longitudinal de suas principais manifestações no processo de aquisição do português por uma criança. Tese de doutorado inédita. UNICAMP.

(1995) Erro e enigma na aquisição da linguagem. Letras de Hoje, 102, Edição Especial. Atas do III Encontro Nacional sobre Aquisição da Linguagem: 145-163.

(1999) Aquisição do verbos prefixados por des em português. Palavra, 5 (no prelo).

FILLMORE, C. J. (1968) The case for case. In: E. Bach, \& R. T. Harms (eds.) Universals in Linguistic Theory.N. Y.: Holt, Reinhart \& Winston.

FISHER, C., D. G. HALL, S. RAKOWITZ \& L. GLEITMAN (1994) When it is better to receive than to give: syntactic and conceptual constraints on vocaburary growth. In: L. Gleitman \& B. Landau (eds.) The Acquisition of the Lexicon. Cambridge, Mass.: The MIT Press.

FODOR, J. (1983) The Modularity of Mind: An Essay onFaculty Psycology. Cambridge, Mass.: The MIT Press.

GARDNER, H. (1986) The Mind's New Science: A History of the Cognitive Revolution. New York: Basic Books.

GEBARA, E. M. S. ( 1978) Marcas aspectuais nos primeiros estágios do desenvolvimento lingüístico. Anais do III Encontro Nacional de Lingüística. PUC-Rio.

(1985) Intonação e processos dialógicos: fusão ou diferenciação. Aquisição da Linguagem. Série Estudos, CCHLFIU: 56-74.

GLEITMAN, L. R. (1990) The structural sources of verb meanings. Language Acquisition, 1: 3-55. 
GRIMM-CABRAL, L. (1998) Conhecimento do léxico e a compreensão em leitura. In: L. Grimm-Cabral \& E. Gorski (eds.) Lingüística e Ensino. Florianópolis: Insular.

GRIMSHAW, J. (1990) Argument Structure. Linguistic Inquiry Monograph, 18. Cambridge, Mass,: The MIT Press.

GRODZINKY, Y. (1990) Theoretical perspectives on language deficits. Cambridge, Mass: MIT Press.

GUIMARÃES, A. M. M. (1994) Desenvolvimento da criança na fase de letramento. Cadernos de Estudos Lingüísticos, 26: 103-110.

HALLIDAY, M.A.K. (1975) Learning How to Mean. London: Anold.

HAMBURGER, H. \& K. WEXLER (1973) Identifiability of transformational grammars. In: K.J.J. Hintikka, J. M. E. Moravicsik \& P. Suppes (eds.) Approaches to Natural Language. Dordrech: Reidel.

(1975) A mathematical theory of learing transformational grammar. Journal of Mathematical Psychology, 12: 137-157.

HARRIS, T. \& K. WEXLER (1996) The Optional Infinite Stage in Child English: Evidence from negations. In: H. Clahsen (ed.) Generative Perspectives on Language Acquisition. Amsterdam: John Benjamin.

HERNANDORENA, C.L.M. (1995) Sobre a descrição de desvios fonológicos e de fenômenos da aquisição da fonologia. Letras de Hoje 30 (4):.91-110. (1996) Relações implicacionais na aquisição da fonologia. Letras de Hoje, 31 (2): 67-76. 1996.

(1999a) Tendências dos estudos em aquisição da fonologia do português brasileiro: A pertinência dos modelos gerativos. Letras de Hoje, Volume Especial.

(1999b) Aquisição da Fonologia e implicações teóricas: um estudo sobre as soantes palatais. In: Lamprecht, R.R. (org.) Aquisição da Linguagem: Questões e Análises. Porto Alegre: EDIPUCRS.

HIRSH-PASEK, K. \& GOLINKOFF, R. M. (1991) Language comprehension: a new look at some old themes. In: N. Krasnegor, D. Rumbaugh, M. Studdert-Kennedy \& R. Schiefelbusch (eds.) Biological and Behavioral Aspects of Language Acquisition. Hillsdale, N. J.: Lawrence Erlbaun.

HOOKWAY , C.(1994) Quine. E, S. Guttenplan (ed.) A Companion to the Philophy of Mind. Oxford: Blackwell.

HYMES, N. (1986) Language acquistion and the theory of parameters. Dordrecht: Reidel.

INGRAM, D. (1989) First Language Acquisition: Method, Description and Explanation. Cambridge: CUP.

INHELDER, B. (1980) Cognitive schemes and their possible relativons to language acquisition. In: M. Piatelli-Palmerini (ed.) Language and 
Learning: The Debate between Jean Piaget and Noam Chomsky. Cambridge, Mass.: Harvard University Press.

JACKENDOFF, R. (1983) Semantics and Cognition. Cambridge, Mass.: The MIT Press.

LIER-DE VITO, M.F \& L.M. ARANTES (1998) Sobre os efeitos da fala da criança: a heterogeneidade desses efeitos. Letras de Hoje, 112. Atas do IV Encontro Nacional sobre Aquisição da Linguagem, Porto Alegre: 1997. LIGHTFOOT, D. (1989) The child's trigger expercience: degree-0 learnability. Behavioral \& Brain Science, 12 (2): 321-334.

LOCKE, J. L. (1997) Desenvolvimento da capacidade para a linguagem falada. In: P.Fletcher \& B. MacWhinney (eds.) Compêndio da Linguagem da Criança. Porto Alegre: Artes Médicas.

LYONS, J. (1970) Chomsky. London: Fontana.

MACNAMARA, J (1977) From Sign to Language. In: J. Macnamara (ed.) Language Learning and Thought. New York: Academic Press.

MACNEILL, D. (1966) Developmental Psycholinguistics. In: F. Smith \& G. Miller (eds.) The Genesis of Language. Cambridge, Mass: MIT Press.

MacWHINNEY, B. (1987) The competition model. In: B. MacWhinney (ed.) Mechanisms of Language Acquisition. Hillsdale, N.J.: Erlbaum.

MARATSOS, M. P. \& M. CHALKLEY,(1981) The internal language of children's syntax: the ontogenesis and representation of syntactic categories. In: K. Nelson (ed.) Children's Language. vol.2. Hillsdale, N. J.: Erlbaun. New York: Gardner Press.

McCAWLEY, J. D. (1968) The role of semantics in a grammar. In: E. Bach \& R. T. Harms (eds.) Universals of Linguistic Theory. N.Y.: Holt, Rinehart \& Winston.

McSHANE, J. (1980) Learning to Talk. Cambridge: CUP.

MEHLER, J. \& E. DUPOUX (1990) Nascer Humano. Lisboa: Instituto Piaget. MEISEL, J. (1997) Parâmetros na aquisição. In: P.Fletcher \& B. MacWhinney (eds.) Compêndio da Linguagem da Criança. Porto Alegre: Artes Médicas.

MENYUK, P. (1969) Sentences children use. Cambridge, Mass.: MIT Press. (1971) The Acquisition and Development of Language. Englewood Cliffs, N.J.: Prentice-Hall.

MOREHEAD, D. M. \& A MOREHEAD (1974) A Piagetian view of thought and language during the first two years. In: R. L. Shiefelbusch and L.L. Lloyd (eds.) Language Perspectives - Acquisition, Retardation and Invervention. Baltimore: University Park Press.

MOTA, H. B. (1999) Os caminhos na aquisição segmental do português. In: Lamprecht, R.R. (org.) Aquisição da Linguagem: Questões e Análises. 
Porto Alegre: EDIPUCRS.

MOTA MAIA, E. A. (1975) A negação da criança: Reflexões sobre as bases empíricas da teoria gerativo-transformacional. Dissertação de Mestrado. UFRJ.

(1986) Sobre a interpretação dos fatos no desenvolvimento fonológico. In: J. M. Meisel (ed.) Aquisición de Lenguaje / Aquisição da Linguagem. Frankfurt: Vervuert.

MYERS, J.,P.JUSCZYK, KEMLER-NELSON, CHARLES-LUCE, WOODWARD, K. HIRSH-PASEK (1996) Infants sensitivity to word boundaries in fluent speech. Journal of Child Language, 23:1-30.

NAME, M. C. L. (em prep) A aquisição do gênero em Português e Francês.

OCHS, E. \& B.B. SHEIFFELIN (1984) Language acquisition and socialization: three developmental stories and their implications. In: R. Scweder \& R LeVine (eds.) Culture and its Acquistion. N.Y.: CUP.

PENNER, Z. \& J. WISSENBORN (1996) Strong Continuity, Parameter Setting and the Trigger Hierarchy: On the acquisition of DP in Bernese Swiss German and High-German. In: H. Clahsen (ed.) Generative Perspectives on Language Acquisition. Amsterdam: John Benjamin.

PERRONI (SIMÕES), M.C. (1977) Emergência de expressões de relações temporais em crianças brasileiras. Anais do II Encontro Nacional de Lingüística. PUC-Rio.

(1978) Ensaiando narrativas: do "jogo de contar" às protonarrativas. Anais do III Encontro Nacional de Lingüística. PUC-Rio. (1986) A Bela e a Fera da Aquisição da linguagem . In: J. M. Meisel (ed.) Aquisición de Lenguaje / Aquisição da Linguagem. Frankfurt: Vervuert. (1991) Aprendendo a contar mentiras. Cadernos de Estudos Lingüísticos, 21:5-24.

(1999) PARA na gramática infantil do Português Brasileiro. Letras de Hoje. Volume especial.

PETERS, A. (1995) Language segmentation: operating principles for the perception and acquisition of language. In: D.I. Slobin (ed.) The Crosslinguistic Study of Language Acquisition, vol.2: Theoretical Issues. Hillsdale, N. J.: Lawrence Erlbaum.

PIAGET, J. (1959) Language and Thought of the Child.London: Routledge \& Kegan Paul.

(1962) Play, Dreams and Imitation in Childhood. London: Routledge \& Kegan Paul.

(1974) The Child and Reality: Problems of Genetic Psychology. London: Frederick Muller Ltd. (1976) Piaget's Theory. In: B. Inhelder \& H.H. Chipman (eds.) Piaget 
and His School: A Reader in Developmental Psychology. New York: Springer-Verlag.

PIATELLI-PALMERINI, M. (1980) (ed.) Language and Learning: The Debate between Jean Piaget and Noam Chomsky. Cambridge, Mass.: Harvard University Press.

(1994) Ever since language and learning: afterthoughts on the PiagetChomsky debate. Cognition, 50: 315-346.

PINKER, S. (1979) Formal models of language learning. Cognition, 7: 217-283. (1987) The bootstrapping problem of language acquisition. In: B. MacWhinney (ed.) Mechanisms of Language Acquisition. Hillsdale, N.J.: Erlbaum.

(1989) Learnability and Cognition: The Acquisition of Argument Structure. Cambridge, Mass.: The MIT Press.

(1994) How could a child use verb syntax to learn verb semantics? In: Gleitman \& B. Landau (eds.) The Acquisition of the Lexicon. Cambridge, Mass.: The MIT Press.

PLUNKETT, K. (1997) Abordagens conexionistas da aquisição da linguagem. In: P.Fletcher \& B. MacWhinney (eds.) Compêndio da Linguagem da Criança. Porto Alegre: Artes Médicas.

POERCH, J. M.et al. (1998) Contribuições do paradigma conexionista na obtenção do conhecimento lingüístico. Letras de Hoje, 112: 36-62. Atas do IV Encontro Nacional sobre Aquisição da Linguagem, Porto Alegre, 1997

PUSTEJOVSKY, J (1995) The Generative Lexicon. Cambridge, Mass,: The MIT Press.

PYLYSHYN, Z. (1977) What does it take to bootstrap a language? In: J. Macnamara (ed.) Language Learning and Thought. New York: Academic Press.

RAMOS, A.P. F (1999) Processos de estrutura silábica em crianças com desvios fonológicos: a compatibilidade entre o ciclo de soância e um modelo integrado de percepção e produção. In: Lamprecht, R. R. (org.) Aquisição da Linguagem: Questões e Análises. Porto Alegre: EDIPUCRS.

RANDALL, J (1992) The catapult hypothesis: an approach to unlearning. In: J. Weissenbom, H. Goodluck \& T. Roeper (eds.) Theoretical issues in language acquisition. Hillsdale: N. J. Lawrence Erlbaum.

REINHART, T. (1983) Anaphora and Semantic Interpretation. London: Croom Helm.

RODRIGUES, A. (1999) Coordenação e concatenação de orações no desenvolvimento da linguagem. Trabalho apresentado no Simpósio em Processamento da Linguagem do II Encontro Nacional da ABRALIN. 
ROEPER, T. \& J. WEISENBORN (1990) How to make parameters work? Comments on Valian. In: L. Frazier \& J. de Villiers (eds.) Language Processing and Language Acquisition. Dordrecht: Kluwer.

SACHS, J., B. BARD \& M. S .JONHSON (1981) Language learning with restricted input: case studies of two hearing children of deaf parents. Applied Psycholinguistics, 2, 33-54.

SCARPA, E. M. (1990) Intonation and dialogue processes in early speech. In: Conti-Ramsden, G. \& C. Snow (orgs.) Children's language, vol VII. (1999) Interfaces entre componentes e representação na aquisição da prosódia. In: Lamprecht. Aquisição da Linguagem: Questões e Análises. Porto Alegre: EDIPUCRS.

SCHLESINGER, I. M. (1971) Production of utterances and language acquisition. In: D.I. Slobin (ed.) The Ontogenis of Grammar. N.Y.: Academid Press.

SCLIAR-CABRAL, L. (1976) O estado da Psicolingüística no Brasil. Arquivos Brasileiros de Psicologia Aplicada., 28 (3): 146-176.

(1977) A explanação lingüística em gramáticas emergentes. Tese de doutorado, USP.

(1989) Pesquisas sobre aquisição da linguagem no Brasil nos últimos quinze anos. Anais do I Encontro Nacional de Aquisição da Linguagem, CEAAL-PUCRS, Porto Alegre. (1998) Letramento e as perspectivas para o próximo milênio. In: L. GrimmCabral \& E. Gorski (eds.) Lingüística e Ensino. Florianópolis: Insular.

SCOLLON, R. (1979) A Real Early Stage: An Unzipped Condensation of a Dissertation on Child Language. In: E. Ochs \& B.B. Schieffelin (ed.) Developmental Pragmatics. New York: Academic Press.

SHAFER,V., D. SHUCARD, J. SHUCARD \& L. A GERKEN (1998) An eletrophysiological study of infants'sensitivity to the sound patterns of English Speech. Journal of Speech, Language and Hearing Research, 41: 874-886.

SIMÕES, L.J. (1997) Sujeito nulo na aquisição do português do Brasil: resultados quantitativos de um estudo de caso. Letras de Hoje, 32 (4):107124.

SINCLAIR, (1976a) Developmental Psycholinguistics. In: B. Inhelder \& H.H. Chipman Piaget and His School: A Reader in Developmental Psychology. New York: Springer-Verlag. (1976b) Epistemology and the study of language, Id ibid.

SKUSE, D. H. (1993) Extreme deprivation in early childhood. In: D. Bishop \& K. Mogford (eds.) Language Development in Exceptional Circurnstances. Hove: Lawrence Erlbaum.

SLOBIN, D. I. (1973) Cognitive prerequisites for the development of grammar. 
In: C.A. Ferguson \& D. I. Slobin (eds.) Studies of Child Language Development . New York: Holt, Reinehart \& Winston.

SLOBIN, D.I. (1985) Crosslinguistic Evidence for the Language-Making Capacity. In: D.I. Slobin (ed.) The Crosslinguistic Study of Language Acquisition, vol.2: Theoretical Issues. Hillsdale, N. J.: Lawrence Erlbaum.

SMITH, N. \& I-M. TSIMPLI (1995) The Mind of a Savant: Language Learning and Modularity. Oxford: Blackwell.

SNOW, C.E. (1986) Young children's responses to adult sentences of varying complexity. In: P. Fletcher \& M. Garman (1986) Language Acquisition. Cambridge: CUP Second Edition.

SPE LKE, E. (1990). Principles of object perception. Cognitive Science, 14: 2956.

(1994). Initial knowledge: six suggestions. Cognition, 50: 431-445.

SOARES, M.E. (1991) A constituição do discurso coeso: um estudo evolutivo da produção oral e escrita. Tese de doutorado inédita. PUC-Rio. (1997). Aspectos relativos à produção de narrativas por crianças de 3 a 9 anos. Caderno de Estudos Lingüísticos, 26: 72-102.

SWINNEY, D. \& ZURIF, E. (1995) Syntactic processing in aphasia. Brain \& Language, 50: 225-239.

TAVAKOLIAN, S. L. (1981) (ed.) Language Acquisition and Linguistic Theory. Cambridge, Mass.: The MIT Press.

TEIXEIRA, E. R. \& B. L. DAVIES (1999) Phonetic patterns and ambient language influences in the speech acquisition of two Brazilian Portuguese speakers. Trabalho apresentado no VIII International Congress for the Study of Child Language. San Sebastian, 12-16 de julho.

ULLER, M. C. (1990) Um estudo evolutivo da produção e compreensão de relações anafóricas. Dissertação de Mestrado, PUC-RJ.

VYGOTSKY, L.S. (1962) Thought and Language. Cambridge, Mass.: The MIT Press.

WAXMAN, S. R. (1994) The development of an appreciation of specific linkages between linguistic and conceptual organization. In: L. Gleitman \& B. Landau (eds.) The Acquisition of the Lexicon. Cambridge, Mass.: The MIT Press.

YAMADA, J.E. (1992) Laura: A Case for the Modularity of Language. Cambridge, Mass.: The MIT Press. 